\title{
Ambient GABA Constrains the Strength of GABAergic Synapses at Cajal-Retzius Cells in the Developing Visual Cortex
}

\author{
Knut Kirmse and Sergei Kirischuk \\ Sensory and Developmental Physiology Group, Institute of Neurophysiology, Johannes-Mueller-Center of Physiology, Charité-University Medicine Berlin, \\ 10117 Berlin, Germany
}

\begin{abstract}
At early stages of brain development, GABA plays a dual role. It fulfills important trophic functions and provides a major excitatory drive for the immature neuronal network. Here, we investigated whether GABA itself can limit the strength of excitatory GABAergic synapses on Cajal-Retzius (CR) cells in sagittal slices from the mouse visual cortex. (2S)-3-[[(1S)-1-(3,4-dichlorophenyl)ethyl]amino-2hydroxypropyl](phenylmethyl)phosphinic acid (CGP55845), a specific $G_{A B A}$ receptor $\left(G_{B B} A_{B} R\right.$ ) blocker, increased the frequency of spontaneous $\mathrm{Ca}^{2+}$ transients and spontaneous and miniature IPSCs (mIPSCs) but did not affect mIPSC amplitudes or kinetics. CGP55845 significantly increased evoked IPSC (eIPSC) amplitudes and decreased the paired-pulse ratio (PPR). Baclofen, a specific $\mathrm{GABA}_{\mathrm{B}} \mathrm{R}$ agonist, produced opposite effects. The size of the readily releasable pool was not affected by these $\mathrm{GABA}_{\mathrm{B}} \mathrm{R}$ modulators. The same CGP55845 actions were observed at physiological temperatures, but they were abolished after glutamate decarboxylase block with 3-mercaptopropionic acid (3-MP). These results indicate that presynaptic $\mathrm{GABA}_{\mathrm{B}} \mathrm{Rs}$ dynamically regulate GABA release probability. SNAP-5114, a specific GABA transporter-2/3 (GAT-2/3) blocker, enhanced mIPSC frequencies, decreased PPR, and increased eIPSC amplitudes without changing eIPSC kinetics. These effects were blocked by CGP55845 and 3-MP. N0-711, a specific GAT-1 blocker, prolonged eIPSC decay and decreased eIPSC/mIPSC amplitudes. These N0-711-mediated effects were not sensitive to CGP55845 and 3-MP. We conclude that the strength of GABAergic inputs to CR cells is constrained by $\mathrm{GABA}_{\mathrm{B}} \mathrm{Rs}$ that are persistently activated by ambient GABA. The latter is also provided by GAT-2/3 operating in the reversed mode. Presynaptic GAT- 1 functions in the uptake mode and possibly provides GABA for presynaptic vesicle filling.
\end{abstract}

Key words: presynaptic inhibition; $\mathrm{GABA}_{\mathrm{B}}$ receptor; readily releasable pool; release probability; IPSCs; GAT-1; GAT-2/3

\section{Introduction}

The amino acid GABA is the main inhibitory neurotransmitter in the adult mammalian brain. In addition, it has a trophic role during neuronal maturation even before synapses are formed (for review, see Owens and Kriegstein, 2002; Represa and BenAri, 2005). In the rodent neocortex, GABA is already present at embryonic day 14 (E14) (Van Eden et al., 1989). In addition to GABA, other components of the GABA signaling system are available at early developmental stages. $\mathrm{GABA}_{\mathrm{A}}$ receptors $\left(\mathrm{GABA}_{\mathrm{A}} \mathrm{Rs}\right)$ are expressed by precursor cells in the neocortical proliferative zone and are activated by endogenous GABA (LoTurco et al., 1995). A pharmacological block of various GABA

Received 0ct. 18, 2005; revised March 16, 2006; accepted March 16, 2006.

This work was supported by the Charité (project 2006-147 to S.K.). K.K. received a scholarship from the German Research Foundation (Deutsche Forschungsgemeinschaft) as a member of the Graduate School (Graduiertenkollegs) 238. We express our particular gratitude to Prof. R. Grantyn and Dr. C. Henneberger for critical reading and helpful comments on previous versions of this manuscript. The technical assistance of Kerstin Rückwardt is highly appreciated.

Correspondence should be addressed to Dr. Sergei Kirischuk, Sensory and Developmental Physiology Group Institute of Neurophysiology, Johannes-Mueller-Center of Physiology, Charité-University Medicine Berlin, Tucholskystrasse 2, 10117 Berlin, Germany. E-mail: sergei.kirischuk@charite.de.

D01:10.1523/JNEUROSCI.0589-06.2006

Copyright $\odot 2006$ Society for Neuroscience $\quad$ 0270-6474/06/264216-12\$15.00/0 receptors $\left(\mathrm{GABA}_{\mathrm{A}}, \mathrm{GABA}_{\mathrm{C}}\right.$, and $\left.\mathrm{GABA}_{\mathrm{B}}\right)$ influences the motility of migrating cells, suggesting that $\mathrm{GABA}$ receptors are functional at this developmental stage (Behar et al., 1996; Manent et al., 2005). GABA transporters (GATs), which are suggested to accelerate GABA clearance from the extracellular space, are expressed in the marginal zone of the neocortex before birth (Minelli et al., 1995; Jursky and Nelson, 1996). Thus, the main components of the GABA signaling system are functional early in development and may contribute to synapse and network formation.

In the neocortex, the first anatomically defined synapses have been observed in the primordial plexiform layer at E14 (Balslev et al., 1996). The postsynaptic sites are most likely formed with the dendrites of Cajal-Retzius (CR) cells. The latter represent a major class of early-generated neurons in the marginal zone (later layer I) of the neocortex. CR cells synthesize and release reelin, a protein that plays a pivotal role in the neocortical layer formation (D’Arcangelo et al., 1995; Hirotsune et al., 1995; Rice and Curran, 2001). Although CR cells constitute a transient population of layer I cells (Frotscher, 1998; for review, see Marin-Padilla, 1998), they form synaptic connections with migrating cortical neurons (Marin-Padilla, 1998) and receive GABAergic (Kilb and Luhmann, 2001; Radnikow et al., 2002; Soda et al., 2003) synaptic inputs. Calcium imaging experiments revealed that CR cells con- 
tribute to the synchronized network activity in layer I of both wild-type and reelin-deficient (reeler) mice (Schwartz et al., 1998; Aguilo et al., 1999). CR cells have been suggested to provide a physiological scaffold for synaptic circuits developing in the cerebral cortex. Interestingly, the action of GABA remains depolarizing in CR cells until these neurons disappear (Mienville, 1998). Consequently, GABAergic over-excitation may induce CR cell degeneration because of an uncontrolled overload of intracellular $\mathrm{Ca}^{2+}$ (excitotoxicity). However, the functional properties of GABAergic inputs on CR cells and the mechanisms that control their strength have not yet been elucidated.

The present study was undertaken to answer the question whether the GABA signaling system controls GABAergic synaptic input to CR cells. It will be shown that $\mathrm{GABA}_{\mathrm{B}} \mathrm{Rs}$ as well as GAT-1 and GAT-2/3 are functional at early postnatal stages and tune GABAergic synaptic transmission. Extracellular GABA determines the GABA release probability via persistently active presynaptic $\mathrm{GABA}_{\mathrm{B}}$ Rs. This ambient GABA-dependent, $\mathrm{GABA}_{\mathrm{B}} \mathrm{R}$ mediated control of GABA release is mediated, at least partially, via GAT-2/3, which operates in the reversed mode releasing GABA into the extracellular space. In contrast to GAT-2/3, presynaptically located GAT-1 functions in the uptake mode, and its blockade leads to a reduction in the quantal IPSC amplitude.

\section{Materials and Methods}

Brain slice preparation. All experiments were conducted with pigmented C57BL/6J mice pups of postnatal day 5 (P5) to P7 (the day of birth was designated as $\mathrm{P} 0$ ). Animals were decapitated under deep ether anesthesia. The brain was removed quickly and transferred into ice-cold saline that contained the following (in mM): $125 \mathrm{NaCl}, 4 \mathrm{KCl}, 10$ glucose, 1.25 $\mathrm{NaH}_{2} \mathrm{PO}_{4}, 25 \mathrm{NaHCO}_{3}, 0.5 \mathrm{CaCl}_{2}$, and $2.5 \mathrm{MgCl}_{2}$, constantly aerated with a $5 \% \mathrm{CO}_{2} / 95 \% \mathrm{O}_{2}$ mixture, $\mathrm{pH} 7.3$. The brain was separated into two hemispheres. Sagittal slices of both hemispheres were cut on a Vibratome (Integraslice 7550PSDS; Campden Instruments, Loughborough, UK). Visual cortex areas 17 and 18 were identified based on the stereotaxic atlas of the mouse brain (Franklin and Paxinos, 1996). After preparation, slices $(200 \mu \mathrm{m}$ thick) were stored for at least $1 \mathrm{~h}$ at room temperature in artificial CSF (ACSF) that contained the following (in mM): $125 \mathrm{NaCl}, 4 \mathrm{KCl}, 10$ glucose, $1.25 \mathrm{NaH}_{2} \mathrm{PO}_{4}, 25 \mathrm{NaHCO}_{3}, 2 \mathrm{CaCl}_{2}$, and $1 \mathrm{MgCl}_{2}$. The $\mathrm{pH}$ was buffered to 7.3 by continuous bubbling with a $5 \% \mathrm{CO}_{2} / 95 \% \mathrm{O}_{2}$ mixture. The osmolarity was $330 \mathrm{mOsm}$. All experiments were performed according to the guidelines laid down by the Office of Health Protection and Technical Safety of the regional government Berlin (Landesamt für Arbeitsschutz, Gesundheitsschutz und technische Sicherheit Berlin, T0406/03).

Electrophysiological recordings in acute slices. For recordings, slices were placed into a recording chamber $(\sim 0.4 \mathrm{ml}$ volume $)$ on the microscope stage (Axioscope FS; Zeiss, Oberkochen, Germany) equipped with phase-contrast optics. Slices were submerged with a constant flow of oxygenated ACSF. Concentrations of $10 \mu \mathrm{M}$ 6,7-dinitroquinoxaline-2,3dione (DNQX; an AMPA/kainate receptor antagonist) and $50 \mu \mathrm{M} \mathrm{DL}-2-$ amino-5-phosphonopentanoic acid (APV; an NMDA receptor blocker) were added to the ACSF to block glutamatergic currents, unless stated otherwise. The flow rate was set to $1 \mathrm{ml} / \mathrm{min}$ using a gravity-driven manually operated superfusion system. A $40 \times$ water-immersion objective (Zeiss) was used in all experiments. IPSCs were recorded using the whole-cell configuration of the patch-clamp technique. The intra-pipette solution contained the following (in $\mathrm{mM}$ ): 100 potassium gluconate, 50 $\mathrm{KCl}, 5 \mathrm{NaCl}, 0.5 \mathrm{CaCl}_{2}$, 5 EGTA, 25 HEPES, $2 \mathrm{MgATP}$, and $0.3 \mathrm{GTP}, \mathrm{pH}$ 7.2 with $\mathrm{KOH}$. The osmolarity was $320 \mathrm{mOsm}$. The pipette resistance was 3-5 $\mathrm{M} \Omega$, when filled with the above saline. Electrophysiological signals were acquired using an EPC-7 amplifier (List, Darmstadt, Germany), a 16-bit analog-digital/digital-analog board (ITC-16; HEKA Elektronik, Lambrecht, Germany), and TIDA 4.11 software (HEKA Elektronik). The signals were filtered at $3 \mathrm{kHz}$ and sampled at a rate of $10 \mathrm{kHz}$.

Access resistance was controlled by applying hyperpolarizing pulses of
$10 \mathrm{mV}$. Cell capacitance and access resistance values were obtained by fitting a monoexponential function to the capacitance artifacts. Only recordings with a series resistance $<30 \mathrm{M} \Omega$ were accepted. Series resistance compensation was not applied. Cells exhibiting $>20 \%$ changes in the access resistance during an experiment were discarded. The chloride reversal potential was approximately $-20 \mathrm{mV}$. The holding potential was set to $-70 \mathrm{mV}$.

CR cell identification. The identification of CR cells in the mouse visual cortex was described previously (Kirmse et al., 2005). Briefly, CR cells were visually selected according to morphological criteria (Hestrin and Armstrong, 1996; Schwartz et al., 1998; Radnikow et al., 2002): (1) location in layer I; (2) horizontal orientation; (3) large ovoid soma; and (4) one thick tapered dendrite typically extended in parallel to the pial surface. Electrophysiologically, CR cells have been shown to exhibit (1) a relatively depolarized resting potential (Mienville and Pesold, 1999) and (2) a hyperpolarization-activated inward $I_{\mathrm{h}}$ current (Kilb and Luhmann, 2000). The resting potential of visually identified CR cells was measured shortly after the establishment of whole-cell configuration, and it ranged from -40 to $-60 \mathrm{mV}$. The injection of hyperpolarizing currents induced a voltage sag, indicating the presence of $I_{\mathrm{h}}$ currents (data not shown).

Electrical stimulation. Evoked postsynaptic currents were elicited by focal electrical stimulation through glass pipettes filled with ACSF $(\sim 10$ $\mathrm{M} \Omega$ ). In this case, QX 314 [N-(2,6-dimethylphenylcarbamoylmethyl)triethylammonium bromide; $2 \mathrm{~mm}$ ] was added to the intracellular solution to prevent generation of action potentials in the tested neurons. An isolated stimulation unit was used to generate rectangular electrical pulses. The pulse duration was set to $0.5 \mathrm{~ms}$.

The following strategy was applied when seeking for a synaptic input on CR cells. The stimulation pipette was slowly moved over layer I, and trains of stimuli (four pulses, $20 \mathrm{~Hz}, 1.5 \mu \mathrm{A}$ ) were applied once per $4 \mathrm{~s}$. The searching protocol was immediately terminated after an evoked IPSC (eIPSC) appearance. Next, paired-pulse stimulation [50 ms interstimulus interval (ISI)] was applied once per $10 \mathrm{~s}$, and stimulus intensity was varied to achieve minimal stimulation (i.e., an activation of a single cell/axon). The reason to use paired-pulse instead of single-pulse stimulation was the high failure rate of the first eIPSC accompanied by strong paired-pulse facilitation (PPF). Simulation was accepted as minimal if the following criteria were satisfied: (1) eIPSC latency remained stable ( $<20 \%$ fluctuations); (2) lowering stimulus intensity by $20 \%$ resulted in a complete failure of eIPSCs; and (3) an increase in stimulus intensity by $20 \%$ changed neither mean eIPSC amplitude nor eIPSC shape. The typical pulse intensity required for minimal stimulation was between 1 and $2 \mu \mathrm{A}$.

Analysis of postsynaptic responses. The present work relies on the assumption that IPSCs could well be approximated by the binomial model of synaptic transmission (Katz, 1969). This model suggests that (1) there are a constant number of release sites $(N)$ that liberate vesicles with an average probability of $p_{\mathrm{r}}$, (2) a single vesicle produces an invariant (quantal) IPSC ( $q$ ), (3) all release sites are independent, and (4) each release site liberates either a single vesicle or nothing in response to an action potential. In the frame of the binomial model, the mean eIPSC amplitude is given by the following equation:

Mean eIPSC $=N \times p_{\mathrm{r}} \times q$.

Two approaches were applied to estimate the quantal size. First, miniature IPSCs (mIPSCs) were recorded in the presence of tetrodotoxin (TTX; $1 \mu \mathrm{M}$ ). Because mIPSC distribution was skewed to the right, the median instead of mean mIPSC amplitude was calculated for each cell and taken as a $q$ estimate. Second, postsynaptic currents were elicited applying trains of pulses (40 stimuli) at different frequencies. The late eIPSC amplitude was defined as the mean eIPSC amplitude in response to the last 20 stimuli excluding failures and was taken as a $q$ estimate (see also Results).

The number of release sites is difficult to measure directly. Therefore, the size of the readily releasable pool (RRP) has been used frequently as its approximate (Schneggenburger et al., 1999; Lu and Trussell, 2000; Kirischuk and Grantyn, 2003). To estimate the RRP, we used highfrequency stimulation $(20 \mathrm{~Hz}, 40$ pulses; see also Results). Repetitive stimulation leads to a decrease in the eIPSC amplitudes. Assuming that 
the eIPSC depression is primarily caused by a transient decrease in the number of readily releasable quanta, it is possible to estimate the RRP size on the basis of the cumulative eIPSC amplitude plot (Schneggenburger et al., 1999; Lu and Trussell, 2000; Kirischuk and Grantyn, 2003). Namely, cumulative eIPSC amplitudes were plotted versus stimulus number. After $10-20$ pulses, the cumulative eIPSCs reached a steady state, as indicated by the linear slope dependence of the cumulative eIPSC amplitude on the pulse number (see Fig. 6 C). Assuming that (1) the number of release sites remains constant throughout the experiment and (2) the linear component reflects vesicle recycling, the cumulative IPSC amplitude in the absence of pool replenishment can be estimated by backextrapolation to the start of the train. Note that RRP estimations were performed without preceding or following mIPSC measurements. Therefore, the RRP in this work has a dimension of picoamperes and represents the product of $N$ and $q$. Release probability $\left(p_{\mathrm{r}}\right)$ was calculated using the above equation, namely $p_{\mathrm{r}}=$ mean eIPSC/RRP.

To apply the above method, one has to measure the amplitudes of stimulus-locked eIPSCs. However, high-frequency stimulation strongly increases the frequency of asynchronous events. To discriminate between stimulus-locked and asynchronous IPSCs, IPSCs that peaked within a 3 $\mathrm{ms}$ interval after the end of a stimulus pulse will be referred to as stimulus-locked eIPSCs (for details, see Kirischuk et al., 2005). To measure eIPSC amplitudes, a linear fit of the decay of the preceding IPSC was first subtracted from each event. Because spontaneous IPSC frequency was usually much lower than $0.5 \mathrm{~Hz}$ (see Results and Fig. 1), a possible contribution of spontaneous IPSCs originating from nonstimulated synaptic contacts was ignored.

$\mathrm{Ca}^{2+}$ imaging. The detailed description of the method was given previously (Kirischuk and Verkhratsky, 1996). In this study, we used Oregon Green 488 BAPTA-1 (OGB1) to measure intracellular $\left[\mathrm{Ca}^{2+}\right]$ changes. Slices were incubated in ACSF supplemented with $5 \mu \mathrm{M}$ OGB1-AM and $0.02 \%$ pluronic F-127 (Molecular Probes, Eugene, OR) for $20 \mathrm{~min}$ at $36^{\circ} \mathrm{C}$. After loading, slices were washed twice with ACSF and stored in ACSF for at least $20 \mathrm{~min}$ at room temperature to ensure deesterification. For recording, slices were transferred to the experimental chamber. The excitation wavelength was controlled by a fast monochromator system, and a cooled CCD camera was used to record fluorescence signals (TILL Photonics, München, Germany). OGB1 was excited at $490 \mathrm{~nm}$. The excitation and emission light was separated using a $510 \mathrm{~nm}$ dichroic mirror. Emitted light was filtered using a $530 \mathrm{~nm}$ long-pass filter. Images were acquired and evaluated using Vision 4.0 software (TILL Photonics). All measurements were performed using $4 \times 4$ binning. The exposure time was set to $400 \mathrm{~ms}$. The acquisition rate was one image per $1 \mathrm{~s}$. The background fluorescence was calculated from a region in the immediate vicinity of the tested cell and subtracted. Fluorescence signals were expressed as relative changes from prestimulus levels $\left(\Delta F / F_{0}\right)$.

Superfusion. All experiments were performed at room temperature $\left(22-25^{\circ} \mathrm{C}\right.$ ), unless stated otherwise (see Fig. 7). Low (1 mM) $\mathrm{Ca}^{2+}$ containing ACSF was prepared by equimolar replacement of $\mathrm{Ca}^{2+}$ by $\mathrm{Mg}^{2+}$. In high (4 mM) $\mathrm{Ca}^{2+}$-containing ACSF, $\mathrm{MgCl}_{2}$ was omitted and $\left[\mathrm{Ca}^{2+}\right]$ was set to $4 \mathrm{~mm}$. TTX was obtained from Alomone Labs (Jerusalem, Israel). (2S)-3-[[(1S)-1-(3,4-dichlorophenyl)ethyl] amino-2-hydroxypropyl] (phenylmethyl)phosphinic acid (CGP55845) and SNAP-5114 were from Tocris (Bristol, UK). All other chemicals were obtained from Sigma-Aldrich (Munich, Germany).

Data evaluation and statistics. Data were evaluated off-line. eIPSCs were analyzed using TIDA 4.11 (HEKA Elektronik). PeakCount 3.2 (C. Henneberger, Berlin, Germany) was used to analyze mIPSCs. This software uses a derivative threshold-crossing algorithm to detect individual postsynaptic events. Each automatically detected event is displayed for visual inspection. The mIPSC rise time (10-90\%) and decay time constant (single exponential fit) can be also obtained. All results are presented as mean \pm SEM. The error bars in all figures indicate SEM. Differences between means were tested for significance using paired Student's $t$ test, unless stated otherwise. The asterisks indicate the following: ${ }^{\star} p<0.05,{ }^{* *} p<0.01$, and ${ }^{\star * *} p<0.001$.

\section{Results}

\section{$\mathrm{GABA}_{\mathrm{B}}$ Rs contribute to cortical network excitability}

Spontaneous synaptic currents were observed in the vast majority of CR cells studied. The mean frequency of spontaneous postsynaptic events was $0.08 \pm 0.01 \mathrm{~Hz}$ (range, $0.004-0.32 \mathrm{~Hz} ; n=37$ ). In line with previous studies (Kilb and Luhmann, 2001; Soda et al., 2003), spontaneous postsynaptic currents were insensitive to the glutamate receptor antagonists APV $(50 \mu \mathrm{M})$ and DNQX (10 $\mu \mathrm{M}$; data not shown), but they were completely and reversibly blocked by $10 \mu \mathrm{M}$ bicuculline methiodide (BMI), revealing their GABAergic nature (data not shown). Below, GABA ${ }_{A}$ R-mediated postsynaptic currents will be referred to as IPSCs even though the action of GABA is depolarizing in CR cells (Mienville, 1998).

$\mathrm{GABA}_{\mathrm{B}}$ Rs have been shown to be expressed in the developing neocortex as early as at E14 (Lopez-Bendito et al., 2002), and their block affected the motility of migrating cells (Behar et al., 1996). To examine whether $\mathrm{GABA}_{\mathrm{B}}$ Rs influence the activity of the immature network, we applied CGP55845, a specific $\mathrm{GABA}_{\mathrm{B}} \mathrm{R}$ antagonist. CGP55845 $(1 \mu \mathrm{M})$ significantly increased spontaneous IPSC (sIPSC) frequency, and this effect was partially reversible (Fig. 1A). The corresponding values were $0.11 \pm 0.02$ and $0.20 \pm$ $0.03 \mathrm{~Hz}$ in the control and in the presence of CGP55845, respectively ( $p<0.05 ; n=5)$. $\mathrm{GABA}_{\mathrm{B}} \mathrm{R}$ block also increased mean sIPSC amplitude by $20 \%(p<0.05 ; n=5)$. Next, CR cells were bulk loaded with the $\mathrm{Ca}^{2+}$ indicator OGB1, and intracellular $\left[\mathrm{Ca}^{2+}\right]$ changes were recorded using the calcium imaging technique (Fig. $1 B$ ). As GABA action in CR cells is depolarizing, an elevated network activity could lead to an increase in $\mathrm{Ca}^{2+}$ influx. CGP55845 had no effect on the resting $\left[\mathrm{Ca}^{2+}\right]$, but it significantly enhanced the frequency of $\mathrm{Ca}^{2+}$ transients in CR cells (Fig. 1C). The respective values were $0.02 \pm 0.01 \mathrm{~Hz}$ in the control and $0.05 \pm 0.02 \mathrm{~Hz}$ in the presence of CGP55845 $(n=7 ; p<0.05)$ (Fig. $1 C$ ). Moreover, $\mathrm{Ca}^{2+}$ transients depended on $\mathrm{GABA}_{\mathrm{A}} \mathrm{R}$ activation, because they were completely and reversibly blocked by $10 \mu \mathrm{M}$ BMI (Fig. $1 C$ ). We conclude that $\mathrm{GABA}_{\mathrm{B}}$ Rs are functional and modulate the network activity of the postnatal neocortex.

\section{$\mathrm{GABA}_{\mathrm{B}}$ Rs are expressed presynaptically}

In principle, the CGP55845-induced increase in sIPSC frequency and amplitude may have a postsynaptic as well as presynaptic origin. If $\mathrm{GABA}_{\mathrm{B}} \mathrm{R}$ blockers affected postsynaptic sites, for instance by decreasing a $\mathrm{K}^{+}$conductance, CGP55845 would be expected to influence the holding current and/or membrane resistance. This was not the case. The mean holding current was $-6 \pm 10 \mathrm{pA}$ (range, -70 to $12 \mathrm{pA}$ ) and $-3 \pm 14 \mathrm{pA}$ (range, -85 to $14 \mathrm{pA}$ ) in the control and in the presence of CGP55845, respectively $(n=11 ; p>0.65)$. The membrane resistance was $760 \pm$ $105 \mathrm{M} \Omega$ (range, 350-1230 $\mathrm{M} \Omega$ ) and $685 \pm 110 \mathrm{M} \Omega$ (range, 290-1200 M $\Omega$ ) in the control and in the presence of CGP55845, respectively $(n=11 ; p>0.1)$. This result supports the previous notion (Lopez-Bendito et al., 2002) that CR cells do not express functional $\mathrm{GABA}_{\mathrm{B}}$ Rs.

To clarify whether $\mathrm{GABA}_{\mathrm{B}}$ Rs are expressed presynaptically, mIPSCs were recorded in the presence of TTX $(1 \mu \mathrm{M})$, a specific blocker of voltage-sensitive $\mathrm{Na}^{+}$channels. CR cells with reasonably high mIPSC frequencies were selected, and it was found that CGP55845 produced a significant increase in the mIPSC frequency (Fig. $2 A$ ). The respective values were $0.041 \pm 0.008 \mathrm{~Hz}$ in control and $0.053 \pm 0.007 \mathrm{~Hz}$ in the presence of CGP55845 (Fig. $2 B)(n=7 ; p<0.05)$. On the other hand, CGP55845 had no effect on mIPSC kinetics (Fig. 2C) or mIPSC amplitudes (Fig. 2D, E). The median mIPSC amplitudes were $48.3 \pm 8.3 \mathrm{pA}$ (range, $25-82 \mathrm{pA}$ ) in the control and $46.6 \pm 8.6 \mathrm{pA}$ (range, $25-89 \mathrm{pA}$ ) in 
A

Control
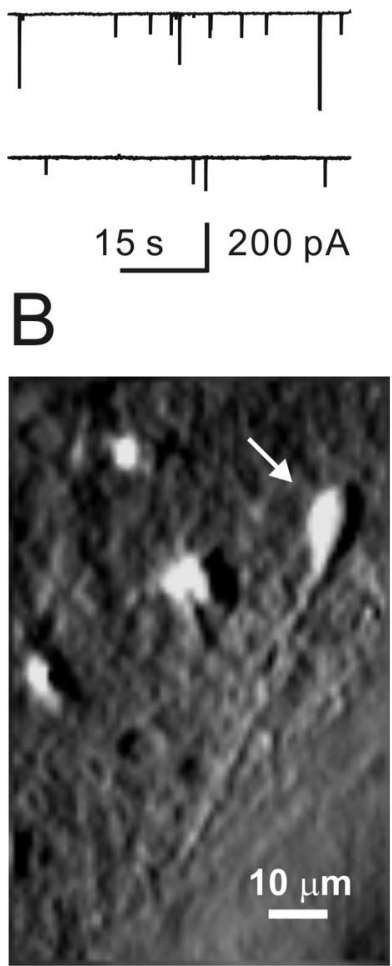

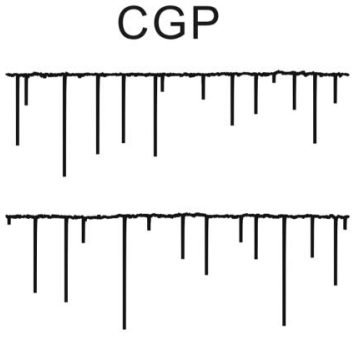

C
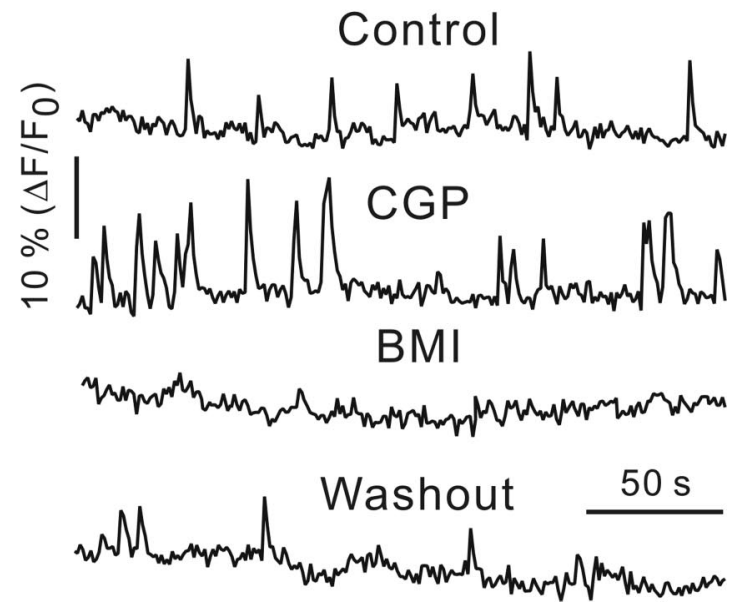

Figure 1. $\mathrm{GABA}_{B} \mathrm{R}$ blockade increased the frequency of sIPSCs and intracellular $\mathrm{Ca}^{2+}$ transients. $A$, Sample traces represent SIPSCs recorded in the control (left), in the presence of CGP55845 (1 $\mu \mathrm{m}$; middle), and after CGP55845 washout (right). B, CR cell (arrow) loaded with 0GB1. The image was modified by applying a shadow filter.C, $\mathrm{Ca}^{2+}$ transients measured in the CR cell (shown in $\boldsymbol{B})$ in the control and in the presence of CGP55845. Note that BMI $(10 \mu \mathrm{M})$ completely and reversibly blocked $\mathrm{Ca}^{2+}$ transients. CGP, CGP55845.

the presence of CGP55845, respectively $(n=7 ; p>0.15)$ (Fig. $2 E)$. We conclude that functional $\mathrm{GABA}_{\mathrm{B}}$ Rs are expressed presynaptically and regulate GABAergic synaptic transmission on CR cells.

\section{$\mathrm{GABA}_{\mathrm{B}} \mathrm{R}$ block affects the paired-pulse plasticity of} GABAergic synaptic transmission

To corroborate this observation, we studied eIPSCs. First, pairedpulse stimulation with variable ISIs was applied, and the pairedpulse ratio (PPR; mean eIPSC ${ }_{2} /$ mean eIPSC $_{1}$ ) was calculated. The intertrial interval was set to $10 \mathrm{~s}$. The minimal number of trials used for PPR calculations was 40. CGP55845 considerably changed the paired-pulse behavior (Fig. $3 A, B$ ). In the control, paired-pulse depression (PPD) was observed at short ISIs (10 and $25 \mathrm{~ms}$ ), whereas PPF dominated at longer ISIs (50-250 ms) (Fig. $3 B)$. In the presence of CGP55845, synaptic connections displayed mainly PPD $(n=4)$ (Fig. $3 B)$.

As the maximal CGP55845 effect was observed at the ISI of 50 $\mathrm{ms}$, the additional experiments were performed using this ISI (Fig. 3C). CGP55845 drastically decreased the PPR. Under control conditions, all CR cells tested at this ISI exhibited PPF (mean PPR, $1.8 \pm 0.2$ ). Application of CGP55845 diminished the PPR to $0.91 \pm 0.14(p<0.01 ; n=9)$ (Fig. 3C,D). The PPR decrease was associated with an increase in the amplitude of the first eIPSCs (Fig. $3 E$ ) and a decrease in the mean failure rate (Fig. $3 F$ ). The respective values were $75 \pm 13$ and $128 \pm 21$ pA for eIPSC am- plitude $(p<0.01 ; n=9)$ and $0.28 \pm 0.05$ and $0.09 \pm 0.03$ for the failure rate $(p<$ $0.001 ; n=9)$ in the control and in the presence of CGP55845, respectively. These results support the conclusion that $\mathrm{GABA}_{\mathrm{B}} \mathrm{Rs}$ are located presynaptically.

$\mathrm{GABA}_{\mathrm{B}} \mathrm{R}$ block facilitates the frequencydependent depression of eIPSCs

Next, we investigated the frequency dependence of $\mathrm{GABA}_{\mathrm{B}} \mathrm{R}$-mediated modulation of eIPSCs. Postsynaptic currents were elicited by trains of 40 pulses at four different stimulation frequencies ranging from 1 to $20 \mathrm{~Hz}$. Only 5-10 trials were performed at each stimulation frequency, to prevent potential frequency-dependent modification of synaptic strength. The intertrial interval was set to $1 \mathrm{~min}$. The amplitudes of eIPSCs usually reached a steady state after $10-15$ pulses. Therefore, the mean amplitude of eIPSCs was calculated using the eIPSC amplitudes in response to the last 20 pulses of each train, excluding failures (late eIPSCs) (Fig. 4A). To allow for comparison, the mean late eIPSCs were normalized to the mean amplitude of the first eIPSC recorded at $1 \mathrm{~Hz}$. A frequency-dependent depression of eIPSC amplitude was observed under all conditions (Fig. $4 B$ ). Even at $1 \mathrm{~Hz}$, the normalized late eIPSC amplitude was $0.78 \pm 0.06$ ( $p<0.05 ; n=6$; one-population Student's $t$ test). Next, the late eIPSC amplitudes in CGP55845 were normalized to the controls. Figure $4 C$ shows that at low frequencies $(<20 \mathrm{~Hz})$, CGP55845 significantly reduced the late eIPSC amplitudes (minimal $p<0.05 ; n=$ 5-10; one-population Student's $t$ test). These data show that activation of presynaptic $\mathrm{GABA}_{\mathrm{B}} \mathrm{Rs}$ reduces the frequencydependent depression of GABAergic synaptic inputs to CR cells.

$\mathrm{GABA}_{\mathrm{B}}$ Rs control the release probability but not the size of the RRP of presynaptic vesicles

$\mathrm{GABA}_{\mathrm{B}}$ Rs belong to the family of G-protein-coupled receptors, activation of which can modulate adenylyl cyclase activity. Intracellular cAMP may, in turn, have an effect on transmitter release probability (Kaneko and Takahashi, 2004; Thakur et al., 2004), the number of primed vesicles [RRP (Nagy et al., 2004; Thakur et al., 2004)], and/or the rate of new vesicle recruitment (Sakaba and Neher, 2003; Kidokoro et al., 2004). We have tried to separate the above parameters by using the binomial model of synaptic transmission. In the frame of the binomial model, the mean eIPSC amplitude is the product of the number of release sites $(N)$, the mean release probability $\left(p_{\mathrm{r}}\right)$, and the mean quantal size $(q): \mathrm{eIPSC}_{1}=N \times p_{\mathrm{r}} \times q . \mathrm{GABA}_{\mathrm{B}} \mathrm{R}$ block has been shown not to affect the quantal size (Fig. $2 E$ ). To estimate the size of the RRP, we applied high-frequency stimulation (Fig. $5 A$ ). The latter results in depletion of the presynaptic vesicle pool, and the cumulative eIPSC amplitude plot provides the basis for RRP estimation (see Materials and Methods) (Schneggenburger et al., 1999; Kirischuk and Grantyn, 2003). A train of 40 pulses delivered at 20 $\mathrm{Hz}$ was selected as a standard stimulation protocol for two rea- 
sons. First, during $20 \mathrm{~Hz}$ trains, the mean late eIPSC amplitude $(41 \pm 12 \mathrm{pA} ; n=9)$ was close to the median mIPSC amplitude observed in this preparation $(48 \pm 8 \mathrm{pA})$ (Fig. 2E). These data favor the suggestion that the RRP is depleted after $\sim 20$ pulses and the rate of new vesicle recruitment rather than stimulation frequency determines the late eIPSC amplitudes. Consequently, the latter approaches the amplitude of quantal events. Second, the late eIPSC amplitudes were similar in the control and in the presence of CGP55845 $(41 \pm 12$ and $40 \pm 9 ; n=9 ; p>0.7$; data not shown), which is in line with the observation that CGP55845 does not affect mIPSC amplitude (Fig. 2E).

Figure 5, $B$ and $C$, shows that $\mathrm{GABA}_{\mathrm{B}} \mathrm{R}$ block failed to affect the RRP size ( $533 \pm$ 72 and $536 \pm 77 \mathrm{pA}$ in the control and in the presence of CGP55845, respectively; $p>0.8 ; n=9)$. In contrast, the mean release probability $\left(p_{\mathrm{r}}=\right.$ mean eIPSC $_{1} /$ $\mathrm{RRP})$ significantly increased in the presence of CGP55845. The respective $p_{\mathrm{r}}$ values were $0.11 \pm 0.01$ and $0.27 \pm 0.03$ in the control and in the presence of CGP55845 (Fig. 5D) $(p<0.001 ; n=9)$.

We then investigated whether GAB$A_{B} R$ blockade influences $R R P$ replenishment. A test pulse was applied at different time intervals ( 1 and $3 \mathrm{~s}$ ) after termination of $20 \mathrm{~Hz}$ stimulation (Fig. 5A). The mean amplitudes of test eIPSCs were normalized to the mean amplitudes of the first eIPSCs in the trains. No difference was observed at both intervals (minimal $p>0.3 ; n=9$ ) (Fig. $5 E$ ). Next, we inspected whether CGP55845 changed the steady-state tetanic current (i.e., mean postsynaptic current measured over the last 20 pulses). Its amplitude is dependent on the number of release sites, the quantal amplitude, and the frequency of vesicle liberation at any given release site. The first two parameters were not modified by CGP55845 (Figs. 2E, 5C). Therefore, a change in the steady-state current could be attributed to a change in the vesicle recruitment/ release rate. We found that the steady-state tetanic postsynaptic current was not affected by CGP55845 (107 \pm 9\% of the control value; $n=9 ; p>0.5$; one-population Student's $t$ test; data not shown), suggesting that presynaptic $\mathrm{GABA}_{\mathrm{B}} \mathrm{Rs}$ do not influence the rate of vesicle recruitment. We conclude that presynaptic $\mathrm{GABA}_{\mathrm{B}} \mathrm{R}$ blockade mainly affects the GABA release probability.

\section{Presynaptic $\mathrm{GABA}_{\mathrm{B}} \mathrm{Rs}$ are partially activated by ambient GABA}

The observation that CGP55845, a GABA $\mathrm{B}_{\mathrm{B}}$ blocker, increased the probability of GABA release suggests that $\mathrm{GABA}_{B} \mathrm{Rs}$ are, at least partially, activated under control conditions. To examine the degree of $\mathrm{GABA}_{\mathrm{B}} \mathrm{R}$ activation, we aimed at maximal activation of $\mathrm{GABA}_{B}$ Rs by applying baclofen, a specific $\mathrm{GABA}_{\mathrm{B}} \mathrm{R}$ agonist. Like CGP55845, baclofen $(10 \mu \mathrm{M})$ influenced neither the holding current nor the membrane resistance (data not shown). However, baclofen drastically decreased the eIPSC amplitude, and this effect was reverted by CGP55845 (Fig. 6A). Activation/ block of $\mathrm{GABA}_{\mathrm{B}}$ Rs significantly altered the PPR (Fig. $6 B, C$ ), the failure rate (Fig. $6 D$ ), and the eIPSC amplitude (Fig. $6 E$ ), but it
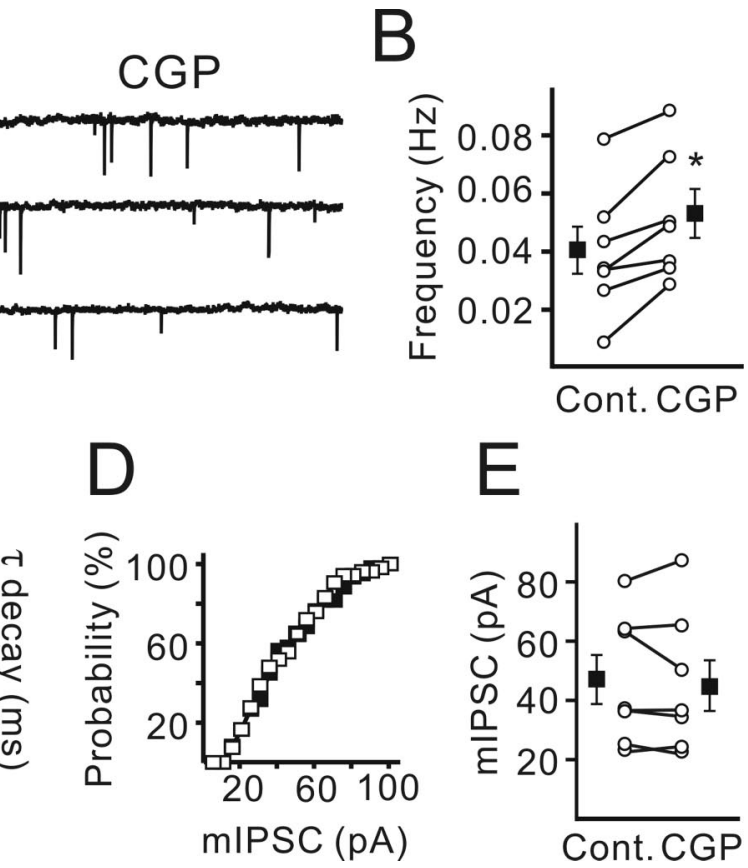

Figure 2. $\quad G_{A B A} R$ blockade increased mIPSC frequency but did not affect the median mIPSC amplitude. $A$, Sample traces show mIPSCs recorded in the control and in the presence of CGP55845. B Statistical data show CGP55845-induced increase in mIPSC requency. Open symbols represent mean values obtained for each cell in the control and in the presence of CGP55845. Filled represent values obtained for each cell in the control and in the presence of CGP55845. Filled symbols represent the mean values $(n=7)$. Error bars indicate SEM. CGP, CGP55845; Cont., control.

did not change the RRP size (Fig. $6 F$ ). Calculated release probabilities were $0.07 \pm 0.02,0.17 \pm 0.02$, and $0.31 \pm 0.07$ in the presence of baclofen, in the control, and in the presence of CGP55845, respectively $(n=5)$ (Fig. $6 G$ ). These data suggest that under control conditions, $\mathrm{GABA}_{\mathrm{B}}$ Rs are only partially activated by ambient GABA. Consequently, changes in extracellular GABA concentration can dynamically alter the strength of GABAergic synapses on CR cells.

To examine whether synaptically released GABA can vary the degree of $\mathrm{GABA}_{\mathrm{B}} \mathrm{R}$ activation, we investigated the relationship between the first and the second eIPSC in individual pairs. If the degree of presynaptic $\mathrm{GABA}_{\mathrm{B}} \mathrm{R}$ activation were altered by synaptically released GABA, a larger IPSC $_{1}$ should be followed by a smaller eIPSC $_{2}$ (i.e., their amplitudes should demonstrate a negative correlation). Indeed, even despite a small number of trials, a negative correlation was observed in 9 of 14 cells tested (Fig. $6 \mathrm{H}$ ). However, the observed negative correlation between eIPSC $_{1}$ and eIPSC $_{2}$ could also reflect the depletion of the RRP: the larger is the first IPSC; the smaller number of vesicles remains available for the following release. If this were the case, CGP55845-induced increase in GABA release probability (Fig. 6G) should result in a stronger RRP depletion and make the above correlation more pronounced. If $\mathrm{GABA}_{\mathrm{B}} \mathrm{R}$ activation contributed to the observed eIPSC ${ }_{1}-\mathrm{eIPSC}_{2}$ relationship, CGP55845 should attenuate the negative correlation between

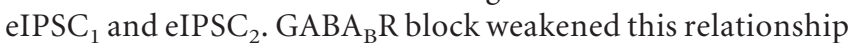
(Fig. 6I). In the presence of CGP55845, a statistically significant correlation between eIPSC $_{1}$ and eIPSC $_{2}$ was observed only in 2 of 14 cells tested. We conclude that synaptically released $G A B A$ can modify the degree of $G_{A B A} R$ activation and affect the following GABA release. 

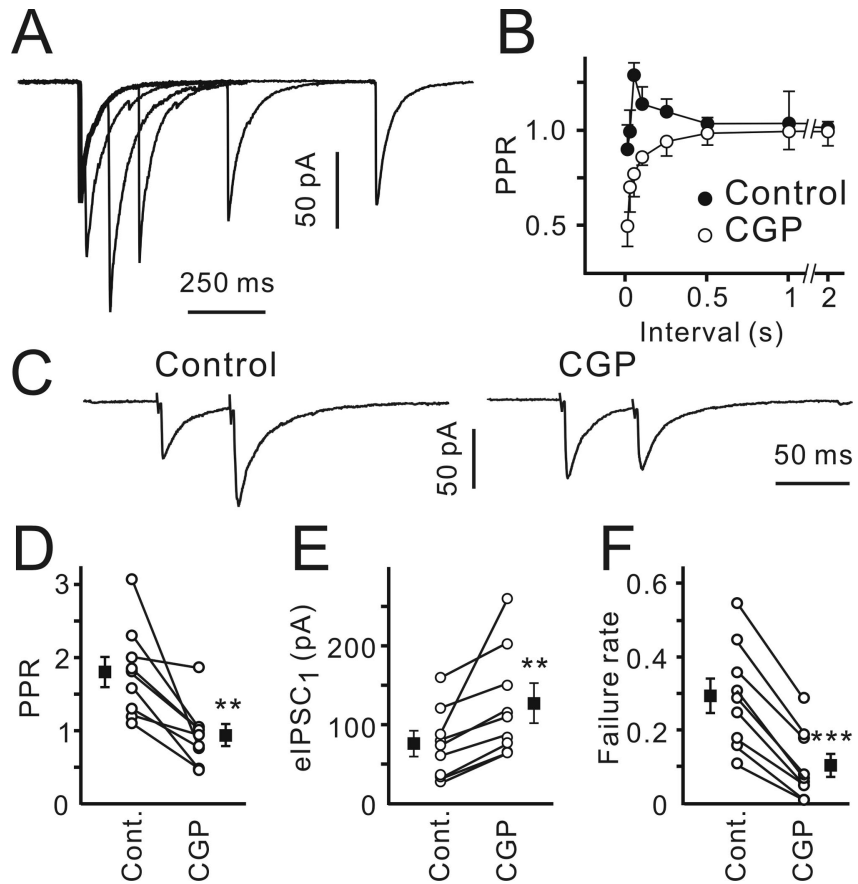

Figure 3. $G A B A_{B} R$ blockade increased the mean elPSC amplitude and decreased the PPR. $A$, Sample traces show elPSCs elicited at different ISIs under control conditions. Traces represent an average of 20 responses. The thick line shows the first eIPSC. $B, P P R$ (mean elPSC $2 /$ mean elPSC $C_{1}$ ) as a function of ISI in the control (filled) and in the presence of CGP55845 (open; $n=4$ ). $C$, Sample traces represent eIPSCs elicited by the paired-pulse stimulation ( $50 \mathrm{~ms} \mid \mathrm{SI})$ in the control (left) and in the presence of CGP55845 (right). Traces represent an average of 40 sequential responses. Data were obtained from the same cell. $\boldsymbol{D}-\boldsymbol{F}$, PPRs $(\boldsymbol{D})$, mean elPSC $\boldsymbol{C}_{1}$ amplitudes $(\boldsymbol{E})$, and elPSC ${ }_{1}$ failure rates $(\boldsymbol{F})$ in the control and in the presence of (GP55845 for each individual experiment. Filled symbols show the mean values $(n=9)$. Error bars indicate SEM. ${ }^{* *} p<0.01$; ${ }^{* * *} p<0$ 0001. CGP, CGP55845; Cont., control.

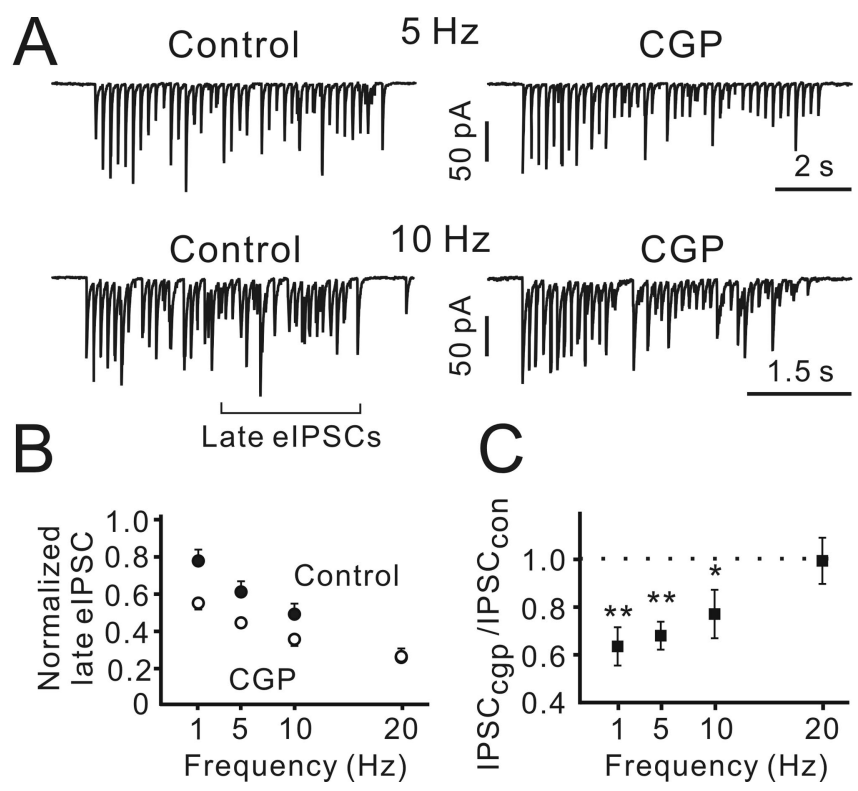

Figure 4. $G A B A_{B} R$ block potentiated frequency-dependent depression of elPSCS. $A$, Sample traces showing individual postsynaptic responses elicited by 5 and $10 \mathrm{~Hz}$ trains (20 pulses) in the control and in the presence of GP55845. B, Late elPSCs recorded at distinct stimulation frequencies. For each CR cell, the mean late elPSC amplitudes were normalized to the mean amplitude of the first elPSC induced by $1 \mathrm{~Hz}$ trains $(n=6)$. C, At low frequencies, late elPSCS recorded in the presence of CGP55845 were significantly smaller than in the controls $(n=$ 5-10). Error bars indicate SEM. ${ }^{*} p<0.05 ;{ }^{* *} p<0.01$. CGP, CGP55845.
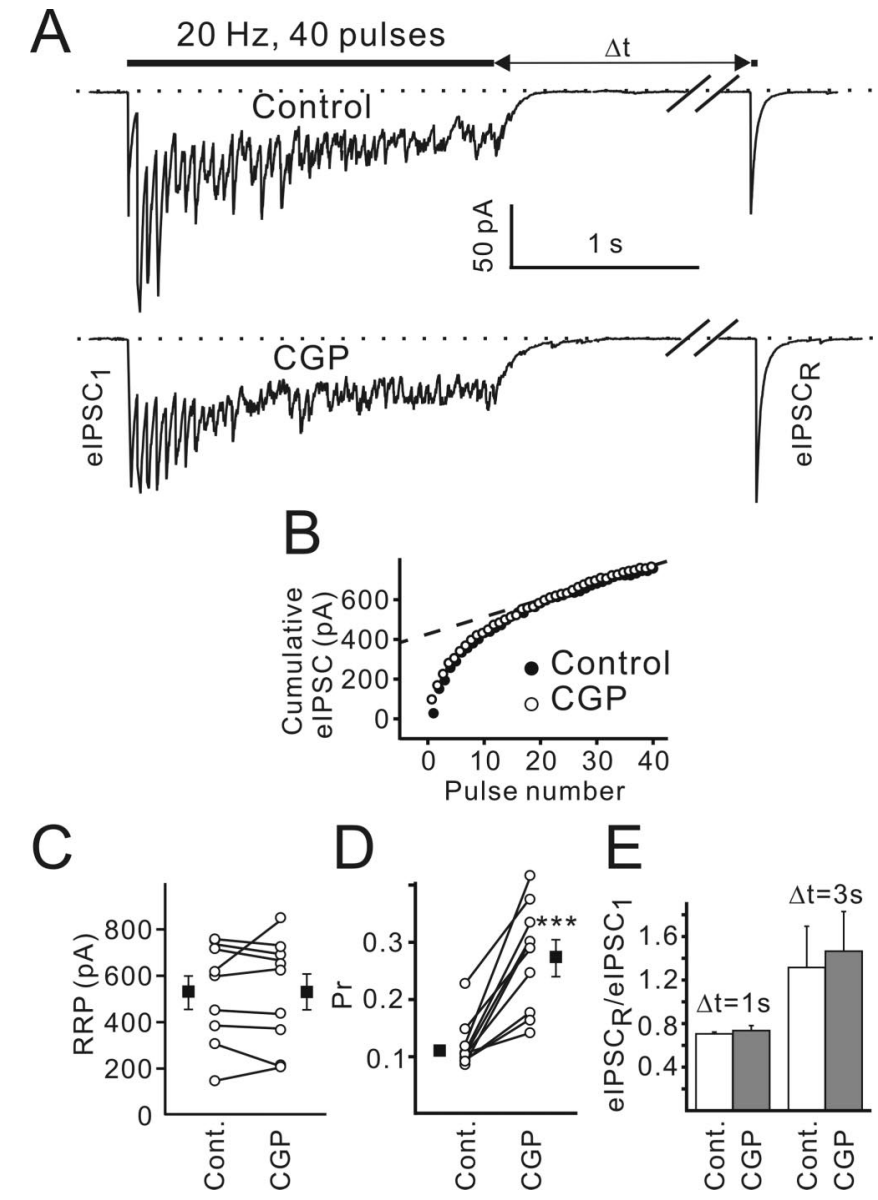

Figure 5. Presynaptic $G A B A_{B} R s$ control release probability without affecting the size of the RRP of presynaptic vesicles. $A$, Sample traces show postsynaptic responses elicited by a 40 stimuli train delivered at $20 \mathrm{~Hz}$ in the control (top trace) and in the presence of (GP55845 (bottom trace). elPSC $C_{R}$ was elicited by a test pulse applied 1 or $3 \mathrm{~s}(\Delta t)$ after the termination of stimulation. Traces represent an average of five sequential responses. Both traces were recorded from the same cell. $\boldsymbol{B}$, elPSC amplitudes were summed to determine the cumulative elPSC amplitude during trains. Each data point is an average of five trials. SEMs are not shown for clarity. The last 20 points (from 21st to 40th pulses) were fitted by linear regression (dashed line) and back-extrapolated to time 0 (see Materials and Methods). C, RRP sizes obtained in the control and in the presence of CGP55845 plotted for each individual experiment. Filled symbols show mean values $(n=9 ; p=0.9)$. $\boldsymbol{D}$, Calculated release probabilities are plotted in the control and after CGP55845 application for each individual experiment. Filled symbols show mean values $\left(n=9 ;{ }^{* * *} p<0.001\right)$. $\boldsymbol{E}$, RRP recovery was not affected by CGP55845 $(p>0.3 ; n=9)$. Error bars indicate SEM. CGP, CGP55845; Cont., control.

Presynaptic $\mathrm{GABA}_{\mathrm{B}} \mathrm{Rs}$ are tonically activated at near physiological temperatures

Because GABA metabolism is temperature dependent, we examined whether CGP55845 affects GABAergic transmission at $34^{\circ} \mathrm{C}$, which is much closer to physiological temperatures. The higher temperatures led to an acceleration of eIPSC decay from $23 \pm 1$ $\mathrm{ms}(n=34)$ at room temperatures to $16 \pm 3 \mathrm{~ms}$ at $34^{\circ} \mathrm{C}(n=9$; $p<0.01$; unpaired Student's $t$ test). However, the CGP55845 effects on GABAergic synaptic transmission were similar to those at room temperature. The PPR was reduced from $1.34 \pm 0.12$ in the control to $0.97 \pm 0.06$ in the presence of CGP55845 ( $p<$ $0.01 ; n=7$ ) (Fig. $7 A, B)$. The calculated release probabilities were $0.15 \pm 0.01$ and $0.22 \pm 0.01$ in the control and in the presence of CGP55845 $(n=7 ; p<0.01)$ (Fig. $7 B)$. These data suggest that tonic activation of presynaptic $\mathrm{GABA}_{\mathrm{B}} \mathrm{Rs}$ is also present at near physiological temperatures. 

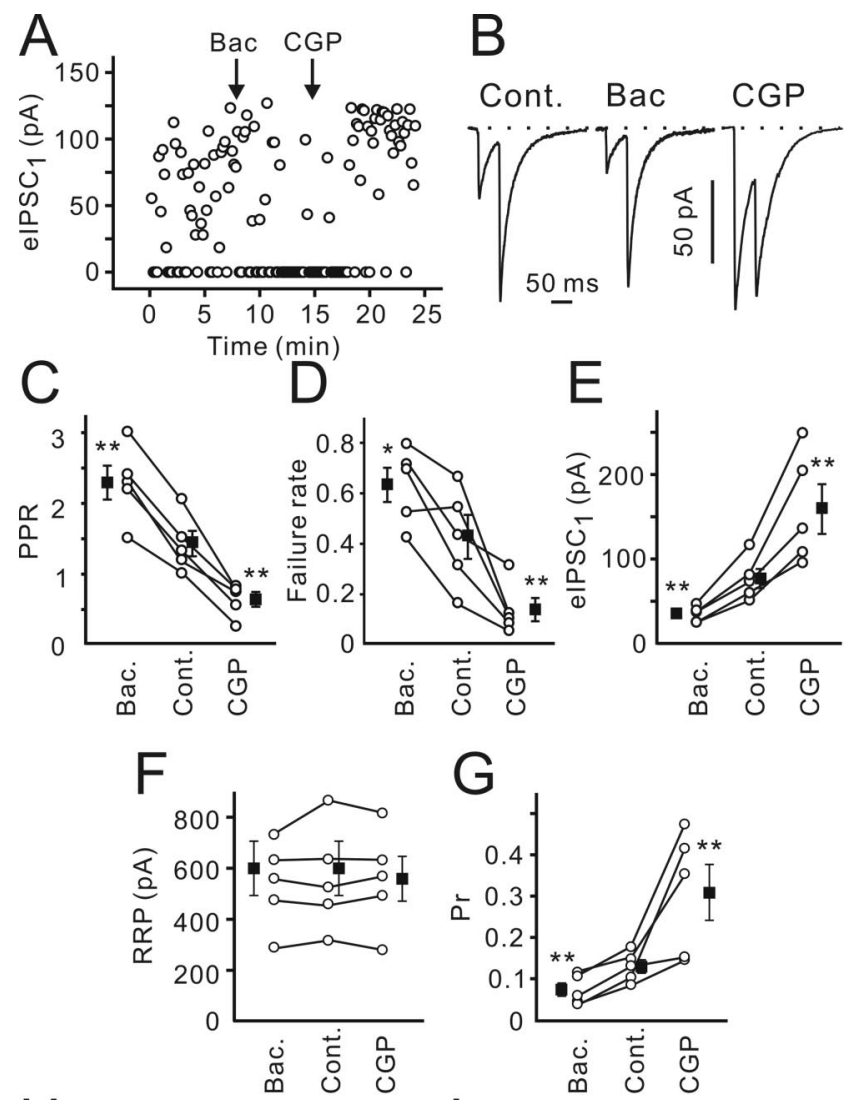

$\mathrm{H}$
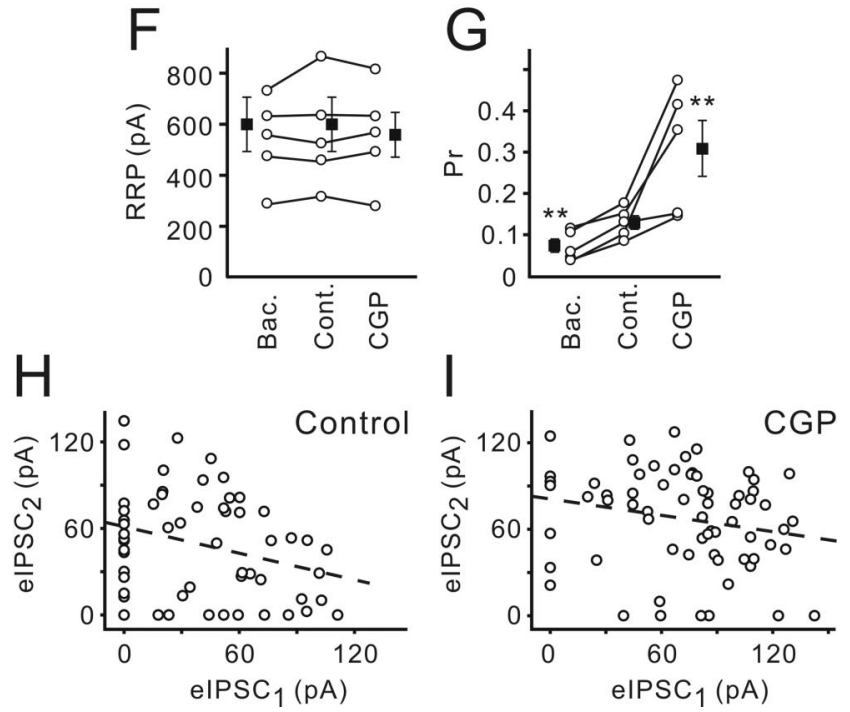

Figure 6. Presynaptic $G A B A_{B} R s$ are only partially activated under control conditions. $A$, Single experiment in which elPSC sensitivity to the $G_{A B A_{B} R}$ agonist baclofen $(10 \mu \mathrm{M})$ and the antagonist CGP55845 $(1 \mu \mathrm{M})$ was verified. Note a delay between baclofen/CGP55845 application and elPSC amplitude changes. $B$, Paired-pulse stimulation $(50 \mathrm{~ms} / \mathrm{SI})$ induced elPSCs in the control and in the presence of either baclofen or CGP55845. Traces represent an average of 40 sequential responses. $\boldsymbol{C}-\boldsymbol{G}, \operatorname{PPRs}(\boldsymbol{C})$, failure rates $(\boldsymbol{D})$, mean elPSC $\boldsymbol{C}_{1}$ amplitudes $(\boldsymbol{E})$, $\operatorname{RRPs}(\boldsymbol{F})$, and calculated release probabilities $(\boldsymbol{G})$ obtained in the control and in the presence of either baclofen or CGP55845 for each individual experiment. Filled symbols show the respective mean values $(n=5) . \boldsymbol{H}, \boldsymbol{I}$, Plots of the second elPSC amplitude against the first elPSC amplitude in individual pairs in the control $(\boldsymbol{H})$ and in the presence of CGP55845 $(1 \mu \mathrm{m} ; \boldsymbol{I})$. Data were obtained from the same $C R$ cell. Dashed lines represent the results of linear regression. Error bars indicate SEM. ${ }^{*} p<0.05$; ${ }^{* *} p<0.01$. Bac, Baclofen; CGP, CGP55845; Cont., control.

\section{Inhibition of GABA synthesis abolished tonic activation of presynaptic $\mathrm{GABA}_{\mathrm{B}} \mathrm{Rs}$}

Next, we investigated whether blockade of GABA synthesis has an effect on the $\mathrm{GABA}_{\mathrm{B}} \mathrm{R}$-mediated presynaptic inhibition. Glutamate decarboxylase (GAD) was suppressed by 3-mercaptopropionic acid (3-MP). Extracellular GABA concentration has been shown to decrease after 3-MP (1 mM) treatment for $1 \mathrm{~h}$ (Golan et al., 1996). Therefore, slices were preincubated in ACSF supplemented with $1 \mathrm{~mm} 3-\mathrm{MP}$ for $>1 \mathrm{~h}$. During the recordings, ACSF contained 100 $\mu \mathrm{M}$ 3-MP. GAD blockade increased the mIPSC frequency $(0.07 \pm 0.02, n=5$, vs $0.04 \pm 0.01$ in the control, $n=7 ; p<0.05)$ without affecting the mIPSC amplitudes ( $42 \pm 5 \mathrm{pA}, n=5$, vs
A

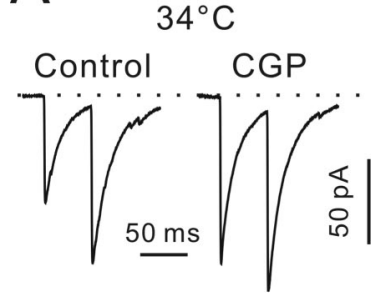

C

B

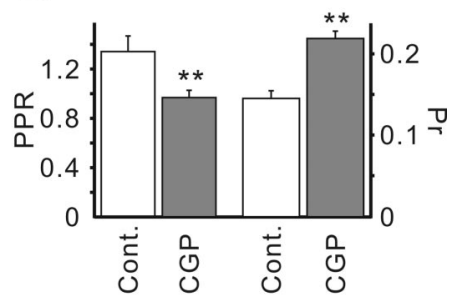

$\mathrm{D}$
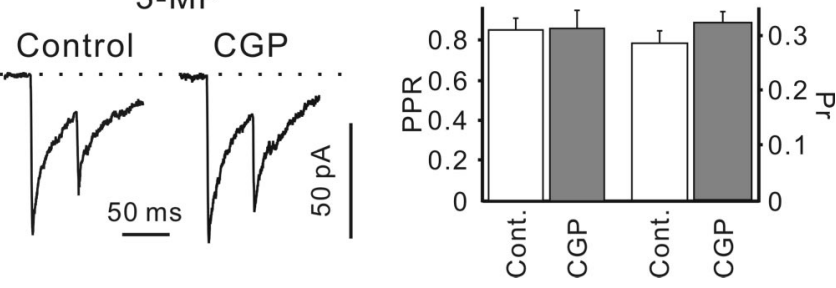

Figure 7. Dependence of presynaptic $\mathrm{GABA}_{B} \mathrm{R}$ activation on temperature and $\mathrm{GAD}$ activity. $\boldsymbol{A}$, Sample traces represent eIPSCs elicited by paired-pulse stimulation in the control and in the presence of CGP55845. Traces represent an average of 40 sequential responses. Data were obtained from the same cell. $\boldsymbol{B}$, Statistical data showing CGP55845 effects on PPRand release probability at $34^{\circ} \mathrm{C}(n=7)$. ${ }^{* *} p<0.01$. C, Paired-pulse elPSCs recorded when GAD was blocked with 3-MP (100 $\mu \mathrm{m}$, but after $>1 \mathrm{~h}$ preincubation with $1 \mathrm{~mm} 3-\mathrm{MP})$. Traces represent an average of 40 sequential responses. Data were obtained from the same cell. D, Statistical data showing CGP55845 effects on PPR and release probability $(n=6)$. Error bars indicate SEM. CGP, CGP55845; Cont., control.

$48 \pm 3 \mathrm{pA}$ in the control, $n=7 ; p>0.2 ;$ unpaired Student's $t$ test; data not shown). In addition, PPR observed in the presence of 3 -MP $(0.91 \pm 0.06 ; n=19)$ was significantly smaller than the control value ( $1.5 \pm 0.1 ; n=29 ; p<0.001$; unpaired Student's $t$ test). Moreover, in the presence of 3-MP, CGP55845 failed to affect the $\operatorname{PPR}(0.86 \pm 0.06$ vs $0.87 \pm 0.09 ; p>0.8)$ (Fig. $7 C, D)$ and GABA release probability $(0.29 \pm 0.02$ vs $0.32 \pm 0.02 ; n=6$; $p>0.2$ ) (Fig. $7 D$ ). The calculated GABA release probabilities were not significantly different from the controls observed in the standard ACSF supplemented with CGP55845 (Fig. 5D) (0.27 \pm $0.03 ; n=9 ; p>0.4$; unpaired Student's $t$ test). This suggests that an inhibitory action of extracellular GABA is influenced by the GAD-dependent GABA synthesis and release.

\section{GABA released via GAT-2/3 partially mediates tonic activation of $\mathrm{GABA}_{\mathrm{B}} \mathrm{Rs}$}

The extracellular GABA level is mainly regulated by specific, high-affinity, $\mathrm{Na}^{+} / \mathrm{Cl}^{-}$-dependent transporters. The high intracellular chloride concentration of immature neurons may potentially have the consequence that GAT functions in the reversed mode (i.e., it releases GABA) (Schwartz, 1987; Taylor and Gordon-Weeks, 1991). Although four distinct GABA transporters have been identified, two of them, GAT-1 and GAT-3, have been shown to be expressed in the marginal zone (Minelli et al., 1995, 1996). GAT-3 expression is strong at birth and further increases during the first week of life (Minelli et al., 2003b). Because GAT-3 is not confined to the vicinity of GABAergic synapses, it is assumed to play a dominant role in controlling extracellular GABA concentration in the developing cortex (Jursky and Nelson, 1996; Minelli et al., 1996). To examine whether GAT-3 affects GABAergic transmission in layer I, we used SNAP5114, a specific GAT-2/3 blocker. First, mIPSCs were recorded in the presence of $1 \mu \mathrm{M}$ TTX. If GAT-2/3 released GABA, its block should attenuate $\mathrm{GABA}_{\mathrm{B}} \mathrm{R}$-mediated presynaptic inhibition and lead to an increase in mIPSC frequency. Indeed, SNAP-5114 (40 


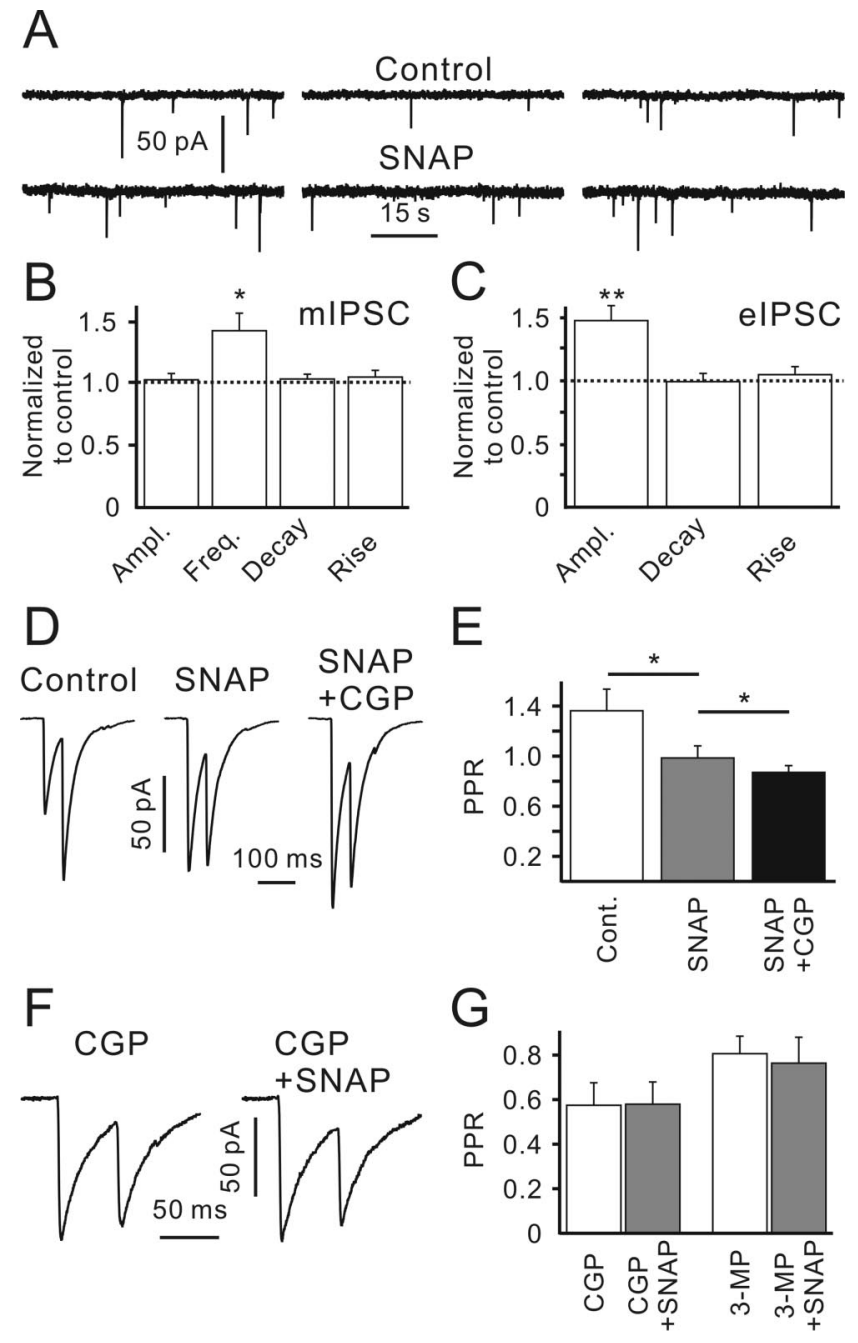

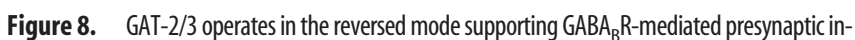
hibition. $A$, Sampletraces showing mIPSCs recorded in the control (top recordings) and in the presence of SNAP-5114 (40 $\mu \mathrm{m}$; bottom recordings). B, SNAP-5114 increased mean mIPSC frequency but did not affect mIPSC amplitude and kinetics. Statistical data were obtained from seven CR cells. C, SNAP5114 increased elPSC amplitude but did not affect eIPSC kinetics $(n=11)$. D, Averaged paired-pulse eIPSCS (40 trials) recorded in the control, in the presence of SNAP-5114, and in the presence of SNAP5114 plus CGP55845. Traces were recorded from the same cell. $\boldsymbol{E}$, SNAP-5114 decreased the PPR. Statistical data were obtained from six CR cells. $\boldsymbol{F}$, Paired-pulse elPSCs recorded in the presence of CGP55845 or CGP55845 plus SNAP-5114. Traces represent an average of 40 sequential responses. Data were obtained from the same cell. G, Statistical data showing SNAP-5114 effects on PPRs in the presence of CGP55845 (left; $n=5$ ) or 3-MP (right; $n=5$ ). Error bars indicateSEM. ${ }^{*} p<0.05$; ${ }^{* *} p<$ 0.01. Ampl., Amplitude; Freq., frequency; CGP, CGP55845; Cont., control.

$\mu \mathrm{M}$ ) increased mIPSC frequency to $144 \pm 5 \%$ of the control ( $p<$ $0.05 ; n=7$; one-population Student's $t$ test) (Fig. $8 A, B$ ) without any significant effect on mIPSC amplitude (103 $\pm 5 \% ; p>0.3$; $n=7$ ) (Fig. $8 B$ ) and kinetics. SNAP-5114 also increased eIPSC amplitudes to $148 \pm 12 \%$ of the control $(p<0.01 ; n=11$; one-population Student's $t$ test) (Fig. $8 C, D$ ) and decreased the PPR from $1.35 \pm 0.18$ to $0.98 \pm 0.07(p<0.01 ; n=6)$ (Fig. $8 D, E)$. Thus, the observed SNAP-5114 effects were quite similar to those of $\mathrm{GABA}_{\mathrm{B}} \mathrm{R}$ blockade with CGP55845 (Figs. 2, 3), suggesting that GAT-2/3 could function in the reversed mode releasing GABA. Application of CGP55845 in the presence of SNAP5114 led to an additional increase in eIPSC amplitude and a decrease in the PPR to $0.86 \pm 0.05$ (Fig. $8 E$ ). These data suggest that tonic $\mathrm{GABA}_{\mathrm{B}} \mathrm{R}$-mediated inhibition is only partially determined by GAT- $2 / 3$ activity. If the observed strengthening of
$\mathrm{GABA}_{\mathrm{B}} \mathrm{R}$-mediated inhibition is the only result of GAT-2/3 blockade, then CGP55845 should make SNAP-5114 ineffective. Indeed, SNAP failed to change both eIPSC amplitudes (102 $\pm 5 \%)$ and the PPR ( $101 \pm 4 \% ; n=5 ; p>0.6$; one-population Student's $t$ test $)$ in the presence of CGP55845 (Fig. $8 F, G$ ). Because the GAT operation mode depends on the intracellular/extracellular GABA concentration (Richerson and Wu, 2003), we inspected whether SNAP-5114 influences GABAergic synaptic transmission when the total amount of GABA is lower. Indeed, when GAD activity was suppressed with $3-\mathrm{MP}$, SNAP did not significantly change eIPSC amplitudes (110 \pm $9 \% ; p>0.25)$ or the PPR $(97 \pm 9 \% ; p>0.7 ; n=5$; one-population Student's $t$ test) (Fig. 8G). Based on the above results, we conclude that GAT-2/3 operates in the reversed mode releasing GABA. The latter activates presynaptic $\mathrm{GABA}_{\mathrm{B}} \mathrm{Rs}$, thereby inhibiting synaptic GABA release.

\section{The quantal amplitude depends on GAT-1 activity}

Because GAT-2/3 blockade did not completely abolish $\mathrm{GABA}_{\mathrm{B}} \mathrm{R}$ mediated inhibition of GABA release (Fig. $8 \mathrm{E}$ ), we asked whether GAT-1 also contributes to the phenomenon. Similar to GAT-2/3, GAT-1 is expressed in neocortical layer I before birth, but in contrast to GAT-2/3, GAT-1 is abundant in presynaptic GABAergic terminals (Minelli et al., 1995; Conti et al., 2004). Therefore, based on the morphological data, GAT-1 seems to be a good candidate to control GABAergic synaptic transmission. To verify the suggestion, we applied NO-711, a specific GAT-1 blocker. First, mIPSCs were recorded in the presence of $1 \mu \mathrm{M}$ TTX. In contrast to GAT-2/3 blockade, NO-711 (10 $\mu \mathrm{M})$ decreased the mIPSC frequency to $77 \pm 6 \%$ of the control $(p<0.05 ; n=7$; one-population Student's $t$ test) (Fig. $9 A, C$ ), but it did not affect mIPSC kinetics (Fig. 9C). This result supports the idea that GAT-1 operates in the uptake mode and its block results in an increase in extracellular GABA concentration and strengthening of $\mathrm{GABA}_{\mathrm{B}} \mathrm{R}$-mediated inhibition. Unexpectedly, GAT-1 blockade led to a decrease in the median mIPSC amplitude in six of seven cells tested. On average, the MIPSC amplitude was decreased to $75 \pm 11 \%$ of the control $(p<0.01 ; n=7$; onepopulation Student's $t$ test) (Fig. 9A-C). NO-711 did not produce an inward current $(n=7)$ (Fig. 9D) or a change in the membrane resistance. Therefore, an attenuation of mIPSCs attributable to postsynaptic shunting seems unlikely. Next, we applied high-frequency $(20 \mathrm{~Hz}, 40$ pulses $)$ stimulation to examine whether NO-711 affected the late eIPSC amplitudes. Indeed, both the RRP size $(70 \pm 8 \% ; p<0.05 ; n=7)$ and the late eIPSC amplitudes $(74 \pm 6 \%$ of the control; $p<0.01 ; n=7$; onepopulation Student's $t$ test) were significantly lowered by NO711 (data not shown). We conclude that GAT-1 block reduces the quantal amplitude. The observed decrease in the mIPSC frequency may therefore reflect a stronger activation of $G_{A B A} R s$, or reduced detection of small mIPSCs, or both.

To investigate the possibilities, we recorded eIPSCs. NO-711 $(10 \mu \mathrm{M})$ decreased the eIPSC amplitudes to $65 \pm 4 \%$ of the control ( $p<0.001 ; n=9$; one-population Student's $t$ test) (Fig. $9 E, F)$. In addition, NO-711 significantly increased the eIPSC decay time constant to $110 \pm 3 \%(p<0.01 ; n=9$; onepopulation Student's $t$ test) (Fig. $9 E$ ). The NO-711 effects on eIPSCs were partially reversible. After a $30 \mathrm{~min}$ washout, the eIPSC amplitude and decay time constant were $87 \pm 4$ and $103 \pm$ $5 \%$ of the controls $(n=3)$ (data not shown). Another GAT-1 blocker, SKF89976A, produced effects similar to those of NO711. SKF89976A $(10 \mu \mathrm{M})$ decreased the eIPSC amplitudes to $73 \pm 5 \%$ and prolonged the eIPSC decay time constant to $107 \pm$ $3 \%(n=3$; data not shown). If GAT-1 took up GABA, its block 


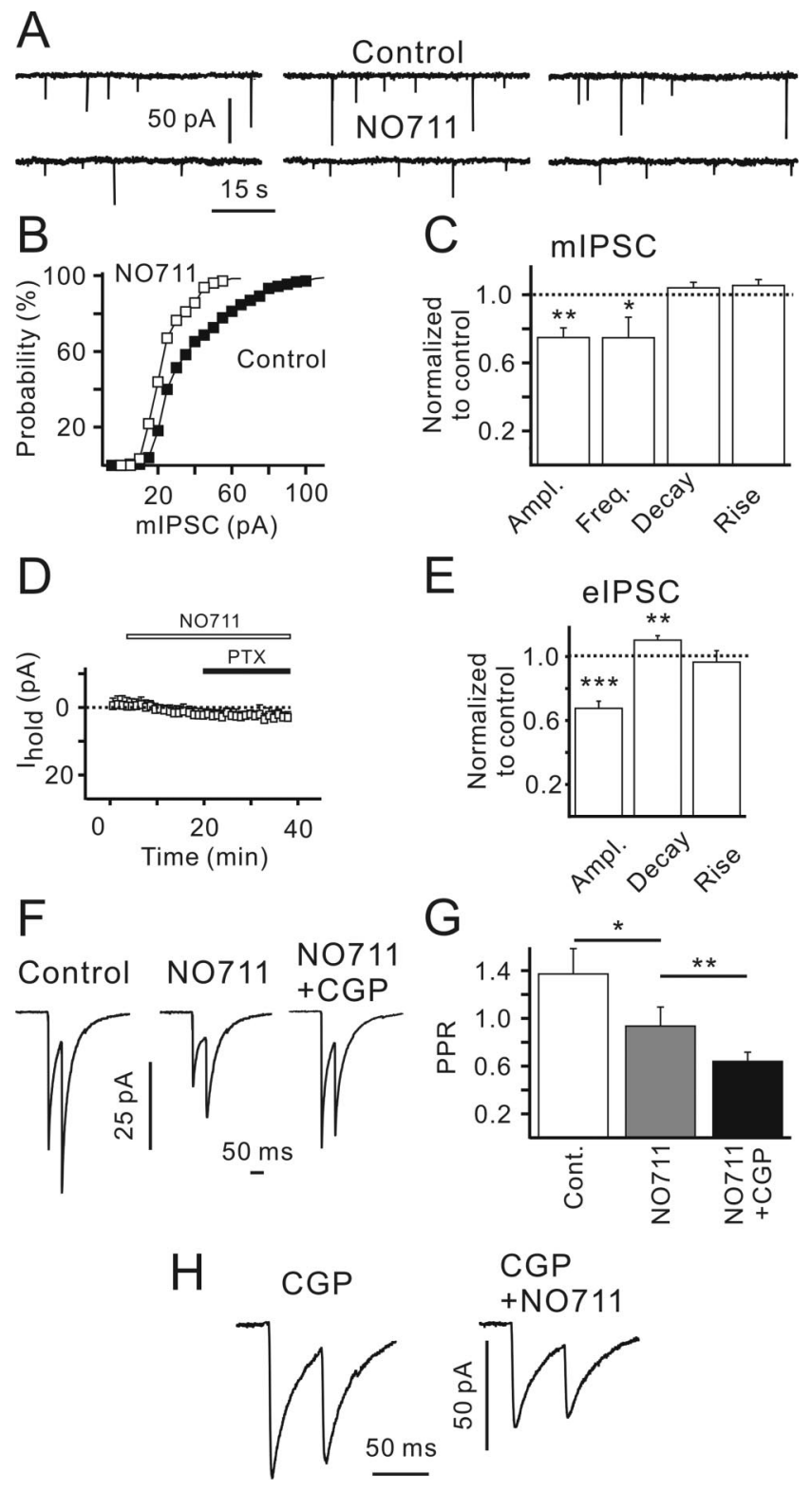

Figure 9. GAT-1 block leads to strengthening of $G A B A_{B} R$-mediated inhibition of synaptic GABA release and a decrease in the quantal size. $\boldsymbol{A}$, Sample traces showing mIPS(s recorded in the control (top recordings) and in the presence of N0-711 (10 $\mu \mathrm{m}$; bottom recordings). Note a decrease in the mIPSC amplitude in the presence of N0-711. B, N0-711 shifted mIPSC amplitude distribution to the left. Data were obtained from a single CR cell. C, N0-711 decreased the median mIPSC amplitude and mean mIPSC frequency but did not affect mIPSC kinetics. Statistical data were obtained from seven CR cells. D, N0-711 and picrotoxin (100 $\mu \mathrm{M})$ did not change the holding current $\left(V_{\text {hold }} ; n=7\right)$. E, N0-711 decreased elPSC amplitude and increased elPSC decay time constant. Statistical data were obtained from nine CR cells. $\boldsymbol{F}$, Averaged paired-pulse elPSCS (40 trials) recorded in the control, in the presence of N0-711, and in the presence of N0-711 plus CGP55845. Traces were recorded from the same cell. G, N0-711 decreased the PPR. Statistical data were obtained from nine CR cells. $\boldsymbol{H}$, Paired-pulse elPSCs recorded in the presence of CGP55845 or CGP55845 plus N0-711. Traces represent an average of 40 sequential responses. Data were obtained from the same cell. ErrorbarsindicateSEM. ${ }^{*} p<0.05 ;{ }^{* *} p<0.01$; ${ }^{* * *} p<0.001$. Ampl.,Amplitude; Freq., frequency; PTX, picrotoxin; (GP, CGP55845; Cont., control.

should lead to an increase in the extracellular GABA concentration, stronger activation of presynaptic $\mathrm{GABA}_{\mathrm{B}} \mathrm{Rs}$, and a decrease in eIPSC amplitudes. This was indeed observed. However, if this were the only effect of GAT-1 blockade, one should also expect an increase in the PPR (similar to the action of baclofen) (Fig. $6 B, C)$. Contrary to this expectation, NO-711 significantly de- creased the PPR from $1.4 \pm 0.2$ to $0.9 \pm 0.2(p<0.05 ; n=9)$ (Fig. 9F,G). Coapplication of CGP55845 increased the first eIPSC amplitude only to the control value $(96 \pm 9 \%$ of the eIPSC amplitude recorded in the control; $p>0.5$; one-population Student's $t$ test) and resulted in a further decrease in the PPR to $0.58 \pm 0.07(n=5)($ Fig. $9 F, G)$. To investigate this unexpected NO-711 effect, CGP55845 was added before NO-711. In this case, NO-711 failed to change the PPR $(0.59 \pm 8$ and $0.58 \pm 9$ in the presence of CGP55845 and CGP55845 plus NO-711; $n=5 ; p>0.6)$ but still reduced eIPSC amplitudes to $69 \pm 5 \%(p<0.01 ; n=5$; one-population Student's $t$ test) (Fig. 9H). Thus, although the discrepancy between NO-711- and baclofen-induced PPR changes requires additional investigations, it can be concluded that the NO711-induced PPR decrease is mediated via $\mathrm{GABA}_{\mathrm{B}} \mathrm{Rs}$.

The NO-711-induced reduction in the quantal amplitude, however, seems to be $\mathrm{GABA}_{B} \mathrm{R}$ independent. This effect may have a postsynaptic [e.g., desensitization of $\mathrm{GABA}_{\mathrm{A}} \mathrm{Rs}$ (Overstreet et al., 2000)] as well as a presynaptic [e.g., decreased vesicle filling (Zhou et al., 2000; Engel et al., 2001)] origin. If the number of postsynaptic $\mathrm{GABA}_{\mathrm{A}}$ Rs available for synaptic transmission were dynamically regulated by extracellular GABA concentration, then varying the latter should affect the quantal amplitude. However, both the 3-MP- and SNAP-5114-induced decrease in $[\mathrm{GABA}]$, as reported by the weakening of $\mathrm{GABA}_{\mathrm{B}} \mathrm{R}$-mediated inhibition, failed to change mIPSC amplitudes (Fig. 8A,B). To corroborate the idea, we modulated synaptic GABA release by using various (namely 1,2 , and $4 \mathrm{~mm}$ ) extracellular $\mathrm{Ca}^{2+}$ concentrations $\left(\left[\mathrm{Ca}^{2+}\right]\right)$. The eIPSC amplitudes and the PPR were dependent on $\left[\mathrm{Ca}^{2+}\right]$ both in the absence and in the presence of CGP55845 (Fig. 10A,B). Elevated $\left[\mathrm{Ca}^{2+}\right]$ also led to an increase in the frequency of mIPSCs from $0.10 \pm 0.06 \mathrm{~Hz}$ in control to $0.18 \pm 0.07(p<0.05 ; n=5$; data not shown $)$. These results confirm that high $\left[\mathrm{Ca}^{2+}\right]$ increased the probability of GABA release and can potentially result in an increase in the extracellular GABA level. However, the median mIPSC amplitudes were not significantly different. The respective values were $41 \pm 7$ and $47 \pm 5 \mathrm{pA}$ in 2 and $4 \mathrm{~mm}\left[\mathrm{Ca}^{2+}\right]$, respectively $(p>0.5 ; n=5)$ (Fig. 10C). This result shows that an increase in spontaneous GABA release does not influence the quantal amplitude. We asked then whether a prolonged presence of GABA in the synaptic cleft can result in a decrease in quantal amplitudes. To test the hypothesis, we applied high-frequency stimulation and measured the late eIPSC amplitudes. The mean amplitude of late eIPSCs was independent of extracellular $\left[\mathrm{Ca}^{2+}\right]$ (Fig. 10D). When normalized to the late eIPSC amplitude obtained in $2 \mathrm{~mm}$ $\left[\mathrm{Ca}^{2+}\right]$, the corresponding values were $101 \pm 7$ and $96 \pm 10 \%$ in 1 and $4 \mathrm{~mm}$ extracellular $\left[\mathrm{Ca}^{2+}\right]$, respectively $(p>0.5 ; n=6$; one-population Student's $t$ test). Further potentiation of GABA release by applying CGP55845 also failed to change the late eIPSC amplitude $\left[39 \pm 3 \mathrm{pA}\right.$ in the control $\left(4 \mathrm{~mm}\left[\mathrm{Ca}^{2+}\right]\right.$ in this case $)$ and $38 \pm 2 \mathrm{pA}$ in the presence of CGP55845; $p>0.7 ; n=6$ ] (Fig. $10 \mathrm{D})$. Thus, both reduction in extracellular [GABA] and potentiation of synaptic GABA release failed to change mIPSC amplitude, when GAT-1 was intact.

It is, however, possible that synaptically located GAT-1 creates a specific environment in the synaptic cleft preserving postsynaptic $\mathrm{GABA}_{\mathrm{A}}$ Rs from detecting extracellular [GABA] changes. If this were the case, a decrease in [GABA] should, at least, weaken the effect of GAT-1 block. As expected, in the presence of 3-MP, NO-711 failed to affect the PPR $(0.85 \pm 11$ vs $0.89 \pm 8 ; n=7 ; p>$ 0.5 ) (Fig. $10 E, F)$. However, it reduced the eIPSC amplitudes to $78 \pm 11 \%(p<0.05 ; n=7$; one-population Student's $t$ test) (Fig. $10 E)$. The latter was not significantly different from the NO-711- 
A $1 \mathrm{mMCa}^{2+} \quad$ B
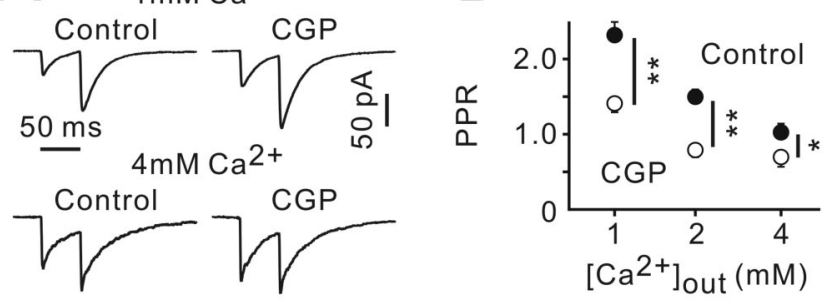

C
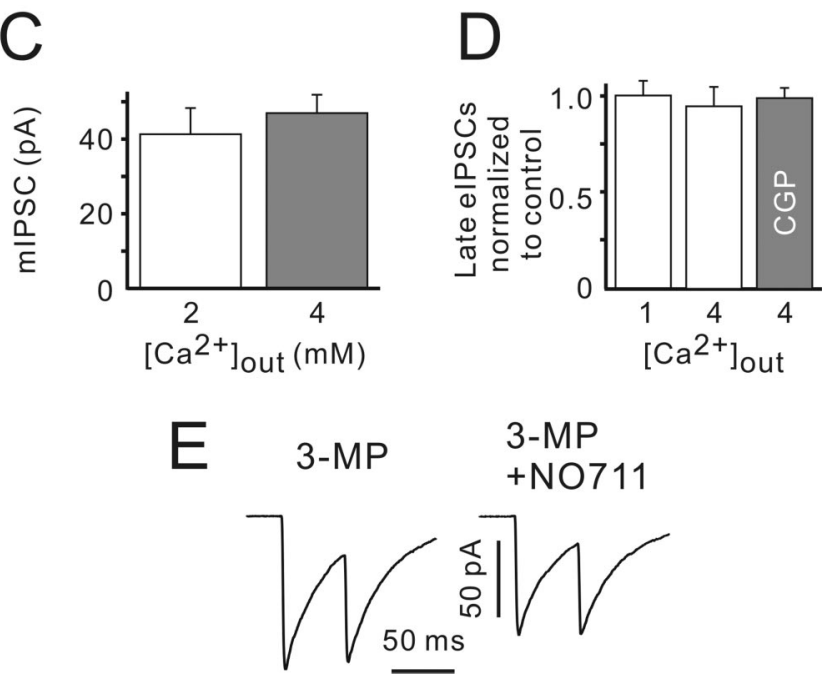

Figure 10. GAT-1 provides GABA for vesicle filling. $A$, Sample recordings show elPSCs in $1 \mathrm{~mm}$ (top) and $4 \mathrm{~mm}$ (bottom) extracellular $\left[\mathrm{Ca}^{2+}\right]$ in the control and in the presence of CGP55845. Traces are an average of 20 trials. The top and bottom pair of traces were obtained from different CR cells. $\boldsymbol{B}$, Dependence of the PPR on the extracellular $\left[\mathrm{Ca}^{2+}\right]$. $\boldsymbol{C}$, Median mIPSC amplitudes were not dependent on extracellular $\left[\mathrm{Ca}^{2+}\right] . \boldsymbol{B}$ and $\boldsymbol{C}$ represent data obtained from seven $(1$ and $4 \mathrm{~mm}$ extracellular $\left.\left[\mathrm{Ca}^{2+}\right]\right)$ and nine (2 mm extracellular $\left.\left[\mathrm{Ca}^{2+}\right]\right) \mathrm{CR}$ cells. D, Late elPSC amplitudes were not dependent on extracellular $\left[\mathrm{Ca}^{2+}\right]$ and $\mathrm{GABA}_{B} \mathrm{R}$ activity. Late elPSCs were normalized to the late elPSC amplitude obtained in standard ( $\left.2 \mathrm{~mm}\left[\mathrm{Ca}^{2+}\right]\right)$ ASCF. Data were obtained from six CR cells. E, Paired-pulse elPSCs recorded when GAD was blocked with 3-MP (100 $\mu \mathrm{m}$, but after $>1 \mathrm{~h}$ preincubation with $1 \mathrm{~mm}$ 3-MP). Traces represent an average of 40 sequential responses. Data were obtained from the same cell. Error bars indicate SEM. ${ }^{*} p<$ $0.05 ;{ }^{* *} p<0.01$. CGP, CGP55845.

induced eIPSC reduction in the absence of 3-MP (65 $\pm 4 \%$; $p>$ $0.3 ; n=9$; unpaired Student's $t$ test) (Fig. 9C). These results favor a presynaptic origin of the NO-711-induced reduction in mIPSC/ eIPSC amplitudes.

\section{Discussion}

Based on patch-clamp recordings of GABAergic synaptic currents from CR cells, we report the following results: (1) the strength of GABAergic synaptic transmission is dynamically regulated by the extracellular GABA concentration; (2) ambient GABA governs the level of presynaptic $\mathrm{GABA}_{\mathrm{B}} \mathrm{R}$ activation and, in turn, controls the probability of GABA release; (3) GAT-2/3 operating in the reversed mode enhances the $\mathrm{GABA}_{\mathrm{B}} \mathrm{R}$-mediated suppression of GABA release; and (4) presynaptically located GAT-1 in the forward mode and its blockade influences the quantal IPSC amplitude.

\section{Functional properties of GABAergic inputs to CR cells}

Despite the fact that GABAergic spontaneous IPSCs (sIPSCs) have been reported in mouse and rat neocortical CR cells (Kilb and Luhmann, 2001; Radnikow et al., 2002; Soda et al., 2003), their physiological properties have not yet been investigated in detail. In the present study, bicuculline-sensitive IPSCs were the only kind of postsynaptic currents encountered. Typically, sIPSC and mIPSC frequency was low (in most cases, $<0.1 \mathrm{~Hz}$ ). Such a low rate of sIPSCs/mIPSCs could be attributed to a small number of synapses (Konig and Marty, 1981; Derer and Derer, 1990). However, electron microscopy studies revealed a large number of GABA-immunoreactive synaptic contacts on the somata and proximal dendrites of CR cells (Radnikow et al., 2002). Immunostaining of the vesicular GABA transporter (VGAT) is intense in layer I at P0-P10 (Minelli et al., 2003a). VGAT-positive puncta are exclusively associated to axonal swellings of the symmetric type and also display GABA immunoreactivity (Minelli et al., 2003a). These data suggest that GABAergic terminals are present on CR cells already at birth and they appear to be sufficiently mature.

Another possibility to explain the low level of spontaneous GABA release at CR cells is that presynaptic vesicles are not "ready" for release. Indeed, rapid rundown of eIPSCs and little variation of eIPSC amplitudes have been reported previously (Radnikow et al., 2002). We applied high-frequency stimulation to estimate the size of the RRP. When normalized to the mean amplitude of late eIPSCs, the mean RRP size was $13 \pm 4$ vesicles (range, $4-29 ; n=32$ ). This is comparable with the mean RRP size at GABAergic synapses in the superior colliculus [24 (Kirischuk et al., 2005)] and the cerebellum [10-15 (Saitow et al., 2005)]. However, mIPSC frequencies observed both in the superior colliculus $[0.1 \mathrm{~Hz}$ (Juttner et al., 2001)] and the cerebellum $[10 \mathrm{~Hz}$ (Saitow et al., 2005)] were much higher than in CR cells. Dendritic filtering of postsynaptic currents could also attenuate the mIPSC amplitudes below the patch-clamp detection threshold. However, the somatic or proximal dendritic location of GABAergic contacts (Radnikow et al., 2002) in combination with the high membrane resistance of CR cells (Kilb and Luhmann, 2001; present work) argues against this suggestion.

Alternatively, the rare occurrence of spontaneous events could result from low release probability of GABA-containing vesicles. Indeed, the release probability of GABAergic synapses on CR cells was lower (0.11) (Fig. 6E) than in other GABAergic synapses of similar age, including those in the superior colliculus (0.25) (Kirischuk et al., 2005). However, block of $\mathrm{GABA}_{\mathrm{B}}$ Rs elevated $p_{\mathrm{r}}$ to about the level observed in other structures (0.27) (Fig. $6 E$ ). This result supports the hypothesis that the low release probability of GABAergic terminals on CR cells is the consequence of $\mathrm{GABA}_{\mathrm{B}} \mathrm{R}$-mediated inhibition of release rather than immaturity of the release apparatus.

\section{$\mathrm{GABA}_{\mathrm{B}} \mathrm{R}$-mediated inhibition of $\mathrm{GABA}$ release}

In the rat neocortex, both $\mathrm{R} 1$ and $\mathrm{R} 2$ subunits of $\mathrm{GABA}_{\mathrm{B}} \mathrm{Rs}$ are present as early as E14. Because heterodimerization of both R1 and $\mathrm{R} 2$ subunits is required for $\mathrm{GABA}_{\mathrm{B}} \mathrm{R}$ formation (White et al., 1998), CR cells have been suggested not to express functional $\mathrm{GABA}_{\mathrm{B}} \mathrm{Rs}$, because they only contain the R1 subunit (LopezBendito et al., 2002). In this study, (1) neither baclofen nor CGP55845 induced a current and/or a change of the membrane resistance in CR cells and (2) mIPSC kinetics, mIPSC amplitude distribution, and median mIPSC amplitude were not affected by CGP55845 (Fig. 2C-E). These results are in line with the above suggestion that $\mathrm{CR}$ cells do not have functional $\mathrm{GABA}_{\mathrm{B}} \mathrm{Rs}$.

On the other hand, eIPSC amplitudes and PPRs were significantly altered by pharmacological block or stimulation of GAB$A_{B}$ Rs (Fig. $6 B$ ). These data suggest that $G_{A B A}$ Rs are present on GABAergic terminals contacting CR cells. Interestingly, both at room and near physiological temperatures, $\mathrm{GABA}_{\mathrm{B}}$ Rs appeared to be persistently active already under control conditions. Tonic 
presynaptic $\mathrm{GABA}_{\mathrm{B}} \mathrm{R}$-mediated inhibition has also been reported in some other preparations (Le Feuvre et al., 1997; Parnas et al., 1999), suggesting that ambient GABA can suppress synaptic GABA release. In the present study, we have shown that $G_{A B A} R$ activation/block only alters GABA release probability without affecting the RRP or mIPSC amplitudes. In addition, GAD blockade with 3-MP abolished $\mathrm{GABA}_{\mathrm{B}} \mathrm{R}$-mediated inhibition without affecting mIPSC amplitudes. The latter observation suggests that extracellular GABA levels also depend on the rate of GABA synthesis. But what are the mechanisms of GABA release? Vesicular release is able to activate presynaptic $\mathrm{GABA}_{\mathrm{B}} \mathrm{Rs}$ because CGP55845 (1) attenuated the negative correlation between the first and the second eIPSC (Fig. $6 H, I$ ) and (2) reduced the amplitude of late eIPSC at low frequencies (Fig. 4). In contrast, GAD blockade enhanced mIPSC frequency but failed to influence mIPSC amplitudes or kinetics (i.e., the total GABA release was increased by $3-\mathrm{MP})$. Consequently, if vesicular GABA release were the main determinant of extracellular GABA levels, one would expect a stronger $\mathrm{GABA}_{\mathrm{B}} \mathrm{R}$-mediated inhibition. Contrary to this expectation, CGP55845 failed to affect both eIPSC amplitudes and paired-pulse behavior in the presence of 3-MP (Fig. $7 C, D)$, suggesting that $\mathrm{GABA}_{\mathrm{B}} \mathrm{R}$-mediated inhibition became even weaker. We conclude that vesicular GABA release can vary the degree of presynaptic $\mathrm{GABA}_{\mathrm{B}} \mathrm{R}$ activation and contribute to short-term plasticity but does not determine the basal $G_{A B A} R$ mediated inhibitory tonus.

\section{GAT-2/3 is functional and operates in the reversed mode}

High-affinity, $\mathrm{Na}^{+} / \mathrm{Cl}^{-}$-dependent GATs operating either in the uptake or reversed mode are suggested to control extracellular GABA levels (Richerson and $\mathrm{Wu}, 2003$ ). In the neonatal neocortex, GAT-3 and GAT-1 immunoreactivity has been shown to be strongest in the marginal zone/layer I (Conti et al., 2004). Because GAT-3-immunopositive spots are not colocalized with GABAergic synapses, GAT-3 is assumed to play a dominant role in controlling extracellular GABA levels (Jursky and Nelson, 1996; Minelli et al., 1996). However, SNAP-5114, a specific GAT-2/3 antagonist, failed to affect amplitudes and/or kinetics of eIPSCs recorded from layer II/III pyramidal cells and layer I interneurons in P17-P22 rat neocortex (Keros and Hablitz, 2005). On the other hand, SNAP-5114 has been reported to increase the amplitudes of eIPSCs in layer V pyramidal cells of P7-P28 rats (Kinney, 2005). Our data are in line with the latter observation. We have shown that SNAP-5114 (1) increased mIPSC frequencies, (2) increased eIPSC amplitudes, and (3) decreased the PPR. These results suggest a presynaptic site of GAT-2/3 action. In addition, blockade of $\mathrm{GABA}_{\mathrm{B}}$ Rs with CGP55845 or GAD with 3-MP abolished the observed SNAP effects (Fig. $8 F, G$ ). This suggests that the SNAP-5114 effects depend on intracellular GABA concentration and are mediated by presynaptic $\mathrm{GABA}_{\mathrm{B}} \mathrm{Rs}$. We therefore conclude that GAT-2/3 operates in the reversed mode releasing GABA. Higher extracellular [GABA] accounts, at least partially, for the observed tonic activation of presynaptic $G_{A B A} R$ s and the resulting inhibition of vesicular GABA release.

\section{Presynaptic GAT-1 supplies GABA for vesicle filling}

GAT-1 is abundant in presynaptic GABAergic terminals (Minelli et al., 1995; Conti et al., 2004) and seemed to be well suited to control GABAergic synaptic transmission. Indeed, GAT-1 inhibitors increase tonic conductance in the cerebellum (Rossi et al., 2003) and the hippocampus (Nusser and Mody, 2002; Semyanov et al., 2003). GAT-1 antagonists prolong eIPSC decay (Thompson and Gahwiler, 1992; Overstreet and Westbrook, 2003; Rossi et al., 2003; Keros and Hablitz, 2005), suggesting that GAT-1 is responsible for GABA clearance from the synaptic cleft. In this study, NO-711 prolonged eIPSC decay, decreased mIPSC frequency, and reduced eIPSC amplitude. These data support the hypothesis that GAT-1 operates in the uptake mode and its block leads to longer GABA presence in the synaptic cleft and a decrease in GABA release probability. However, NO-711 decreased the PPR that points to an increase in GABA release probability. The mechanism of these contradictory NO-711 actions has remained unclear, but we report that the NO-711 effect on the PPR can be blocked by CGP55845 and 3-MP (Figs. 9, 10), suggesting its dependence on ambient GABA-activated $\mathrm{GABA}_{\mathrm{B}}$ Rs. Because the operation mode of GAT is dependent on transmembrane $\mathrm{Na}^{+}$, $\mathrm{Cl}^{-}$, GABA, and potential gradients, the existence of two cell populations in which GAT-1 operates in the forward and reversed modes (see supplemental Fig. 1, available at www.jneurosci. org as supplemental material) seems to provide a suitable explanation for the above inconsistency. However, this working hypothesis definitely needs further investigations.

In addition to its $\mathrm{GABA}_{\mathrm{B}} \mathrm{R}$-mediated effects, NO-711 significantly reduced the quantal size in a $G_{A B A} R$-independent manner. Similar results were reported in the juvenile (P13-P16) hippocampus where NO-711 decreased both mIPSC amplitude and frequency. An NO-711-induced GABA accumulation, followed by desensitization of synaptic $\mathrm{GABA}_{\mathrm{A}} \mathrm{Rs}$, has been suggested to underlie this phenomenon (Overstreet et al., 2000). However, if postsynaptic $\mathrm{GABA}_{\mathrm{A}}$ Rs were partially desensitized by ambient GABA, the number of desensitized $\mathrm{GABA}_{\mathrm{A}}$ Rs would be expected to reflect extracellular [GABA] changes. We performed several experiments (SNAP-5114, 3-MP, high/low extracellular $\left[\mathrm{Ca}^{2+}\right]$ ) directed to manipulate extracellular and synaptic GABA levels but failed to reverse this NO-711 effect on mIPSC/eIPSC amplitudes. Therefore, although $\mathrm{GABA}_{\mathrm{A}} \mathrm{R}$ desensitization cannot be excluded, our data support the alternative idea that presynaptic GAT-1 operates in the uptake mode and its blockade leads to a reduction in presynaptic vesicle filling.

\section{References}

Aguilo A, Schwartz TH, Kumar VS, Peterlin ZA, Tsiola A, Soriano E, Yuste R (1999) Involvement of Cajal-Retzius neurons in spontaneous correlated activity of embryonic and postnatal layer 1 from wild-type and reeler mice. J Neurosci 19:10856-10868.

Balslev Y, Saunders NR, Mollgard K (1996) Synaptogenesis in the neocortical anlage and early developing neocortex of rat embryos. Acta Anat (Basel) 156:2-10.

Behar TN, Li YX, Tran HT, Ma W, Dunlap V, Scott C, Barker JL (1996) GABA stimulates chemotaxis and chemokinesis of embryonic cortical neurons via calcium-dependent mechanisms. J Neurosci 16:1808-1818.

Conti F, Minelli A, Melone M (2004) GABA transporters in the mammalian cerebral cortex: localization, development and pathological implications. Brain Res Brain Res Rev 45:196-212.

D’Arcangelo G, Miao GG, Chen SC, Soares HD, Morgan JI, Curran T (1995) A protein related to extracellular matrix proteins deleted in the mouse mutant reeler. Nature 374:719-723.

Derer P, Derer M (1990) Cajal-Retzius cell ontogenesis and death in mouse brain visualized with horseradish peroxidase and electron microscopy. Neuroscience 36:839-856.

Engel D, Pahner I, Schulze K, Frahm C, Jarry H, Ahnert-Hilger G, Draguhn A (2001) Plasticity of rat central inhibitory synapses through GABA metabolism. J Physiol (Lond) 535:473-482.

Franklin KBJ, Paxinos G (1996) The mouse brain in stereotaxic coordinates. San Diego: Academic.

Frotscher M (1998) Cajal-Retzius cells, reelin, and the formation of layers. Curr Opin Neurobiol 8:570-575.

Golan H, Talpalar AE, Schleifstein-Attias D, Grossman Y (1996) GABA metabolism controls inhibition efficacy in the mammalian CNS. Neurosci Lett 217:25-28. 
Hestrin S, Armstrong WE (1996) Morphology and physiology of cortical neurons in layer I. J Neurosci 16:5290-5300.

Hirotsune S, Takahara T, Sasaki N, Hirose K, Yoshiki A, Ohashi T, Kusakabe M, Murakami Y, Muramatsu M, Watanabe S (1995) The reeler gene encodes a protein with an EGF-like motif expressed by pioneer neurons. Nat Genet 10:77-83.

Jursky F, Nelson N (1996) Developmental expression of GABA transporters GAT1 and GAT4 suggests involvement in brain maturation. J Neurochem 67:857-867.

Juttner R, Meier J, Grantyn R (2001) Slow IPSC kinetics, low levels of alphal subunit expression and paired-pulse depression are distinct properties of neonatal inhibitory GABAergic synaptic connections in the mouse superior colliculus. Eur J Neurosci 13:2088-2098.

Kaneko M, Takahashi T (2004) Presynaptic mechanism underlying cAMPdependent synaptic potentiation. J Neurosci 24:5202-5208.

Katz B (1969) The release of neural transmission substances. Liverpool, UK: Liverpool UP.

Keros S, Hablitz JJ (2005) Subtype-specific GABA transporter antagonists synergistically modulate phasic and tonic $\mathrm{GABA}_{\mathrm{A}}$ conductances in rat neocortex. J Neurophysiol 94:2073-2085.

Kidokoro Y, Kuromi H, Delgado R, Maureira C, Oliva C, Labarca P (2004) Synaptic vesicle pools and plasticity of synaptic transmission at the Drosophila synapse. Brain Res Brain Res Rev 47:18-32.

Kilb W, Luhmann HJ (2000) Characterization of a hyperpolarizationactivated inward current in Cajal-Retzius cells in rat neonatal neocortex. J Neurophysiol 84:1681-1691.

Kilb W, Luhmann HJ (2001) Spontaneous GABAergic postsynaptic currents in Cajal-Retzius cells in neonatal rat cerebral cortex. Eur J Neurosci 13:1387-1390.

Kinney GA (2005) GAT-3 transporters regulate inhibition in the neocortex. J Neurophysiol 94:4533-4537.

Kirischuk S, Grantyn R (2003) Intraterminal $\mathrm{Ca}^{2+}$ concentration and asynchronous release at single GABAergic boutons in rat collicular cultures. J Physiol (Lond) 548:753-764.

Kirischuk S, Verkhratsky A (1996) $\left[\mathrm{Ca}^{2+}\right]_{\mathrm{i}}$ recordings from neural cells in acutely isolated cerebellar slices employing differential loading of the membrane-permeant form of the calcium indicator fura-2. Pflügers Arch 431:977-983.

Kirischuk S, Juttner R, Grantyn R (2005) Time-matched pre- and postsynaptic changes of GABAergic synaptic transmission in the developing mouse superior colliculus. J Physiol (Lond) 563:795-807.

Kirmse K, Grantyn R, Kirischuk S (2005) Developmental downregulation of low-voltage-activated $\mathrm{Ca}^{2+}$ channels in Cajal-Retzius cells of the mouse visual cortex. Eur J Neurosci 21:3269-3276.

Konig N, Marty R (1981) Early neurogenesis and synaptogenesis in cerebral cortex. Bibl Anat 152-160.

Le Feuvre Y, Fricker D, Leresche N (1997) GABA A receptor-mediated IPSCs in rat thalamic sensory nuclei: patterns of discharge and tonic modulation by $\mathrm{GABA}_{\mathrm{B}}$ autoreceptors. J Physiol (Lond) 502:91-104.

Lopez-Bendito G, Shigemoto R, Kulik A, Paulsen O, Fairen A, Lujan R (2002) Expression and distribution of metabotropic GABA receptor subtypes $\mathrm{GABA}_{\mathrm{B}} \mathrm{R} 1$ and $\mathrm{GABA}_{\mathrm{B}} \mathrm{R} 2$ during rat neocortical development. Eur J Neurosci 15:1766-1778.

LoTurco JJ, Owens DF, Heath MJ, Davis MB, Kriegstein AR (1995) GABA and glutamate depolarize cortical progenitor cells and inhibit DNA synthesis. Neuron 15:1287-1298.

Lu T, Trussell LO (2000) Inhibitory transmission mediated by asynchronous transmitter release. Neuron 26:683-694.

Manent JB, Demarque M, Jorquera I, Pellegrino C, Ben-Ari Y, Aniksztejn L, Represa A (2005) A noncanonical release of GABA and glutamate modulates neuronal migration. J Neurosci 25:4755-4765.

Marin-Padilla M (1998) Cajal-Retzius cells and the development of the neocortex. Trends Neurosci 21:64-71.

Mienville JM (1998) Persistent depolarizing action of GABA in rat CajalRetzius cells. J Physiol (Lond) 512:809-817.

Mienville JM, Pesold C (1999) Low resting potential and postnatal upregulation of NMDA receptors may cause Cajal-Retzius cell death. J Neurosci 19:1636-1646.

Minelli A, Brecha NC, Karschin C, DeBiasi S, Conti F (1995) GAT-1, a high-affinity GABA plasma membrane transporter, is localized to neurons and astroglia in the cerebral cortex. J Neurosci 15:7734-7746.

Minelli A, DeBiasi S, Brecha NC, Zuccarello LV, Conti F (1996) GAT-3, a high-affinity GABA plasma membrane transporter, is localized to astrocytic processes, and it is not confined to the vicinity of GABAergic synapses in the cerebral cortex. J Neurosci 16:6255-6264.

Minelli A, Alonso-Nanclares L, Edwards RH, DeFelipe J, Conti F (2003a) Postnatal development of the vesicular GABA transporter in rat cerebral cortex. Neuroscience 117:337-346.

Minelli A, Barbaresi P, Conti F (2003b) Postnatal development of highaffinity plasma membrane GABA transporters GAT-2 and GAT-3 in the rat cerebral cortex. Brain Res Dev Brain Res 142:7-18.

Nagy G, Reim K, Matti U, Brose N, Binz T, Rettig J, Neher E, Sorensen JB (2004) Regulation of releasable vesicle pool sizes by protein kinase A-dependent phosphorylation of SNAP-25. Neuron 41:417-429.

Nusser Z, Mody I (2002) Selective modulation of tonic and phasic inhibitions in dentate gyrus granule cells. J Neurophysiol 87:2624-2628.

Overstreet LS, Westbrook GL (2003) Synapse density regulates independence at unitary inhibitory synapses. J Neurosci 23:2618-2626.

Overstreet LS, Jones MV, Westbrook GL (2000) Slow desensitization regulates the availability of synaptic $\mathrm{GABA}_{\mathrm{A}}$ receptors. J Neurosci 20:7914-7921.

Owens DF, Kriegstein AR (2002) Is there more to GABA than synaptic inhibition? Nat Rev Neurosci 3:715-727.

Parnas I, Rashkovan G, Ong J, Kerr DI (1999) Tonic activation of presynaptic $\mathrm{GABA}_{\mathrm{B}}$ receptors in the opener neuromuscular junction of crayfish. J Neurophysiol 81:1184-1191.

Radnikow G, Feldmeyer D, Lubke J (2002) Axonal projection, input and output synapses, and synaptic physiology of Cajal-Retzius cells in the developing rat neocortex. J Neurosci 22:6908-6919.

Represa A, Ben-Ari Y (2005) Trophic actions of GABA on neuronal development. Trends Neurosci 28:278-283.

Rice DS, Curran T (2001) Role of the reelin signaling pathway in central nervous system development. Annu Rev Neurosci 24:1005-1039.

Richerson GB, Wu Y (2003) Dynamic equilibrium of neurotransmitter transporters: not just for reuptake anymore. J Neurophysiol 90:1363-1374.

Rossi DJ, Hamann M, Attwell D (2003) Multiple modes of GABAergic inhibition of rat cerebellar granule cells. J Physiol (Lond) 548:97-110.

Saitow F, Suzuki H, Konishi S (2005) Beta-adrenoceptor-mediated longterm up-regulation of the release machinery at rat cerebellar GABAergic synapses. J Physiol (Lond) 565:487-502.

Sakaba T, Neher E (2003) Direct modulation of synaptic vesicle priming by $\mathrm{GABA}_{\mathrm{B}}$ receptor activation at a glutamatergic synapse. Nature 424:775-778.

Schneggenburger R, Meyer AC, Neher E (1999) Released fraction and total size of a pool of immediately available transmitter quanta at a calyx synapse. Neuron 23:399-409.

Schwartz EA (1987) Depolarization without calcium can release gammaaminobutyric acid from a retinal neuron. Science 238:350-355.

Schwartz TH, Rabinowitz D, Unni V, Kumar VS, Smetters DK, Tsiola A, Yuste R (1998) Networks of coactive neurons in developing layer 1. Neuron 20:541-552.

Semyanov A, Walker MC, Kullmann DM (2003) GABA uptake regulates cortical excitability via cell type-specific tonic inhibition. Nat Neurosci 6:484-490.

Soda T, Nakashima R, Watanabe D, Nakajima K, Pastan I, Nakanishi S (2003) Segregation and coactivation of developing neocortical layer 1 neurons. J Neurosci 23:6272-6279.

Taylor J, Gordon-Weeks PR (1991) Calcium-independent gammaaminobutyric acid release from growth cones: role of gamma-aminobutyric acid transport. J Neurochem 56:273-280.

Thakur P, Stevens DR, Sheng ZH, Rettig J (2004) Effects of PKA-mediated phosphorylation of snapin on snaptic transmission in cultured hippocampal neurons. J Neurosci 24:6476-6481.

Thompson SM, Gahwiler BH (1992) Effects of the GABA uptake inhibitor tiagabine on inhibitory synaptic potentials in rat hippocampal slice cultures. J Neurophysiol 67:1698-1701.

Van Eden CG, Mrzljak L, Voorn P, Uylings HB (1989) Prenatal development of GABA-ergic neurons in the neocortex of the rat. J Comp Neurol 289:213-227.

White JH, Wise A, Main MJ, Green A, Fraser NJ, Disney GH, Barnes AA, Emson $\mathrm{P}$, Foord SM, Marshall FH (1998) Heterodimerization is required for the formation of a functional $\mathrm{GABA}_{\mathrm{B}}$ receptor. Nature 396:679-682.

Zhou Q, Petersen CC, Nicoll RA (2000) Effects of reduced vesicular filling on synaptic transmission in rat hippocampal neurones. J Physiol (Lond) 525:195-206. 